\title{
Neoichnology of tarantulas (Araneae: Theraphosidae): Criteria for recognizing spider burrows in the fossil record
}

\author{
Daniel I. Hembree
}

\begin{abstract}
The Mygalomorphae, a suborder of heavy bodied spiders that includes tarantulas, first appears in the Triassic. While burrowing is common among extant mygalomorphs, fossil burrows attributable to this group are not well-documented. The goal of this study is to describe the morphology of tarantula burrows and to compare them to the burrows of other large, terrestrial animals with the purpose of improving the interpretation of continental ichnofossils and ancient soil ecosystems. This project involved the study of the burrowing behaviors and burrow morphologies of Hysterocrates gigas, Pelinobius muticus, and Aphonopelma chalcodes (Araneae: Theraphosidae), which inhabit tropical to subtropical forests, scrublands and grasslands, and semi-arid deserts, respectively. Individual tarantulas were placed in sediment-filled terrariums under controlled temperature and moisture conditions according to their environmental preferences. The tarantulas were observed for three to 12 months after which they were removed, and the open burrows were cast with plaster, excavated, and described. Each species constructed burrows by excavating sediment using their chelicerae and pedipalps. Burrow openings were circular to elliptical and lined with thin layers of silk. The tarantulas produced burrows with distinct morphologies: 1) $H$. gigas: vertical shafts with elongate ovoid chambers near the sediment surface and at depth, 2) P. muticus: subvertical sinuous shafts with and without branches, and 3) A. chalcodes: straight to curved, subhorizontal tunnels. Tarantula burrows as a group were also distinct from burrows of trapdoor spiders, scorpions, salamanders, and skinks. Data collected from these neoichnological studies can be applied to continental ichnofossil assemblages in order to better interpret the paleoecology of ancient soil ecosystems.
\end{abstract}

Daniel I. Hembree. Department of Geological Sciences, Ohio University, 316 Clippinger Laboratories, Athens, Ohio 45701, USA. hembree@ohio.edu

Keywords: ichnofossils; trace fossils; continental; arthropod; arachnid; paleoecology

Submission: 5 May 2017 Acceptance:6 September 2017

Hembree, Daniel I. 2017. Neoichnology of tarantulas (Araneae: Theraphosidae): Criteria for recognizing spider burrows in the fossil record. Palaeontologia Electronica 20.3.45A: 1-30

palaeo-electronica.org/content/2017/2003-neoichnology-of-tarantulas

Copyright: September 2017 Palaeontology Association.

This is an open access article distributed under the terms of Attribution-NonCommercial-ShareAlike 4.0 International (CC BY-NC-SA 4.0 ), which permits users to copy and redistribute the material in any medium or format, provided it is not used for commercial purposes and the original author and source are credited, with indications if any changes are made.

creativecommons.org/licenses/by-nc-sa/4.0/creativecommons.org/licenses/by-nc-sa/4.0/ 


\section{INTRODUCTION}

The diversity and abundance of continental trace fossils, particularly those known from paleosols, has increased dramatically in recent years (Hasiotis, 2007; Knaust, 2012). Interpretations of the behaviors and tracemaking organisms that produced these trace fossils has included most ethological categories (dwelling, locomotion, feeding, brooding, etc.) and terrestrial taxa (e.g., Hasiotis, 2002; Seilacher, 2007; Genise, 2017). These interpretations were possible as a result of observations of modern soil animals in natural and laboratory environments (e.g., Hasiotis, 2007; Hembree, 2016). Modern soil animals are abundant and exist in elaborate food webs containing many trophic levels (Lavelle and Spain, 2005). Many of these animals, however, are understudied both taxonomically and ecologically. This is especially true of the biogenic structures that soil animals produce as a result of various behaviors (Hasiotis, 2007).

The body fossil record of arachnids (spiders, scorpions, mites), which includes many burrowing taxa, extends to the Silurian (Dunlop, 2010). Neoichnological studies of various spiders, scorpions, and whip scorpions have shown that not only do arachnids produce recognizable and distinct biogenic structures, but they are also active agents in soil formation (i.e., Sadler, 1993; Hembree et al., 2012; Schmerge et al., 2013; Hembree, 2013, 2014; Hils and Hembree, 2015). Mygalomorph spiders appear in the fossil record approximately 240 million years ago, yet they are rarer than fossils of other groups of spiders (Dunlop et al., 2008). Extant mygalomorph spiders, especially tarantulas, are prolific burrowers, suggesting that their trace fossils may be quite common. A key problem to overcome, however, is the recognition of those trace fossils and distinguishing them from the burrows of other continental animals.

The purpose of this study is to document the burrow morphology of three species of tarantulas, Hysterocrates gigas, Pelinobius muticus, and Aphonopelma chalcodes (Araneae: Theraphosidae), in a controlled laboratory setting. The tarantulas burrowed in sediments with compositions, densities, and moisture modeled after their natural habitats. The goals of this study were to: 1) improve our understanding of the burrowing techniques used by large, ground-dwelling spiders and the behaviors associated with burrows; 2) improve the interpretation of terrestrial arthropod-produced trace fossils; and 3) facilitate the interpretation of the presence of large, ground-dwelling spiders in the fossil record through the recognition of their fossil burrows, improving paleoecological interpretations.

\section{Spider Evolution and Behavior}

Araneae consists of over 46,000 extant species of spiders (World Spider Catalog, 2017) divided into two suborders, the Mesothelae and Opisthothelae (Figure 1.1). Within the Opisthothelae, the infraorder Mygalomorphae contains 2,666 species in 315 genera (World Spider Catalog, 2017). Mygalomorphs are generally bulky, grounddwellers that include both trapdoor spiders and tarantulas. Tarantulas are mygalomorphs grouped within the family Theraphosidae. Extant tarantulas
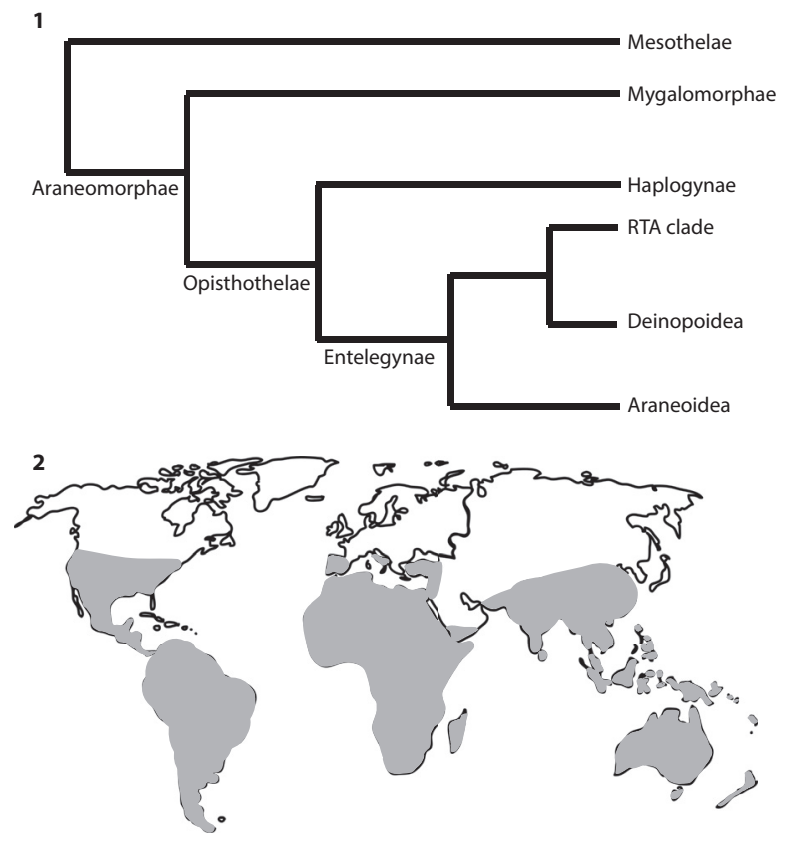

3

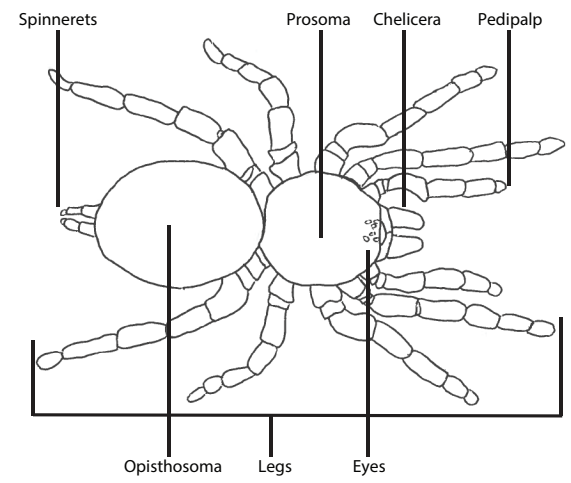

FIGURE 1. 1, Phylogeny of spiders; tarantulas belong to the Mygalomorphae, a basal group of the Opisthothelae. 2, Geographic range of tarantulas. The shaded areas of the map represent known areas containing extant species of tarantulas. 3, Spider morphology. 
inhabit arid to tropical environments and are distributed globally below approximately $50^{\circ} \mathrm{N}$ latitude (Figure 1.2). Tarantulas are terrestrial to arboreal and are important predators in their habitats, feeding on arthropods and small vertebrates.

The bodies of spiders are divided into the anterior prosoma and the posterior opisthosoma (Figure 1.3) (Rupert et al., 2004). In derived spiders, the segments of the prosoma and opisthosoma are fused (Rupert et al., 2004). Spiders have several types of appendages including eight walking legs, two chelicerae with fangs for delivering venom, and two pedipalps. The pedipalps are used to grab and kill prey, assist in reproduction, and to excavate burrows (Pechenik, 1991; Hils and Hembree, 2015). Silk is produced and manipulated using spinnerets at the posterior of the opisthosoma.

The fossil record of Araneae currently consists of approximately 1,185 valid species (Dunlop et al., 2013). The oldest known true fossil spider is a mesothele from the Carboniferous of France (Selden, 1996, 2000). In contrast, the oldest opisthotheles currently described are from the Triassic and consist of a mygalomorph from France (Selden and Gall, 1992) and two araneomorphs from South Africa and the eastern United States (Virginia) (Selden et al., 1999). Only two true tarantulas have been described from the fossil record, which are preserved in amber from the Neogene (Miocene) of the Dominican Republic and Mexico (Wunderlich, 1988; Dunlop et al. 2008).

Most extant mygalomorph spiders construct burrows (Marshall, 1996; Hamilton et al., 2012); however, fossil spider burrows are rare and are reported primarily from the Neogene (Pickford, 2000; Hasiotis, 2002). Spiders use burrows as temporary to permanent dwellings that serve as protection from predators and extreme weather conditions as well as for sites for ambush predation and brooding (Gertsch, 1949; Kotzman, 1990; Pérez-Miles et al., 2005; Machkour M'Rabet et al., 2007; Ferretti and Ferrero, 2008; Hamilton et al., 2012; Hils and Hembree, 2015). Spiders excavate their burrows using both the chelicerae and pedipalps, removing sediment and either carrying and depositing it on the surface or flinging it from the burrow opening (Gertsch, 1949; Hils and Hembree, 2015). Burrow walls may be lined with thin to thick sheets of silk depending on the species and the cohesiveness of the sediment (Gertsch, 1949; Pérez-Miles et al., 2005; Hils and Hembree, 2015). The dimensions of the burrow and its complexity also depend on the species, the size of the individ- ual, and the associated behaviors (Gertsch, 1949; Kotzman, 1990; Pérez-Miles et al., 2005; Machkour M'Rabet et al., 2007; Hils and Hembree, 2015).

Field studies of tarantulas have provided some data concerning the morphology of their burrows (Kotzman, 1990; Pérez-Miles et al., 2005; Machkour M'Rabet et al., 2007), however, these studies have provided limited images of these structures and three-dimensional information. Burrows of the Australian tarantula Selenocosmia stirlingi were described in the field by gradual excavation (Kotzman, 1990). Neither photographs nor drawings of the burrows were provided. These burrows were described as unbranched, vertical shafts, some slightly spiraling or gently curved, 31$100 \mathrm{~cm}$ in length and $\sim 1.5 \mathrm{~cm}$ in diameter, with slightly enlarged, horizontally oriented terminal chambers. Burrows of Eupalaestrus weijenberghi and Acanthoscurria suina from Uruguay were studied in the field and described through excavation and casting with plaster and polyurethane (PérezMiles et al., 2005). A simple line drawing of a burrow was provided for each species. The burrows of both species were described as consisting of a vertical shaft that led to a horizontally oriented, enlarged chamber. In burrows of $E$. weijenberghi a narrow tunnel extended from the end of the chamber. Burrows of $A$. suina were $14 \mathrm{~cm}$ deep with shafts $3 \mathrm{~cm}$ in diameter and $10 \mathrm{~cm}$ in length and chambers $4 \mathrm{~cm}$ wide and $6 \mathrm{~cm}$ long. Burrows of $E$. weijenberghi were $19 \mathrm{~cm}$ deep with shafts $3 \mathrm{~cm}$ in diameter and $11 \mathrm{~cm}$ in length and chambers $4 \mathrm{~cm}$ wide and $9 \mathrm{~cm}$ long; the terminal tube was $2 \mathrm{~cm}$ in diameter and $7 \mathrm{~cm}$ in length. Burrows of the Mexican tarantula Brachypelma vagans were also described through excavation in the field (Machkour M'Rabet et al., 2007). Four general sketches of these burrows were provided. The burrows consisted of vertical to subvertical shafts many of which then led to a horizontal tunnel with lengths of $15-60 \mathrm{~cm}$, widths of $3-5 \mathrm{~cm}$, and depths of $16-40$ $\mathrm{cm}$. Most burrows had at least one chamber, especially those of females, and some had multiple chambers (up to four).

\section{MATERIALS AND METHODS}

Three species of tarantulas were selected for this study: Hysterocrates gigas, Pelinobius muticus, and Aphonopelma chalcodes. These species were selected due to their known burrowing habits, the different behaviors associated with their burrows, and their occurrence in different environments. Hysterocrates gigas (Figure 2.1) inhabits tropical and subtropical forests of West Africa 

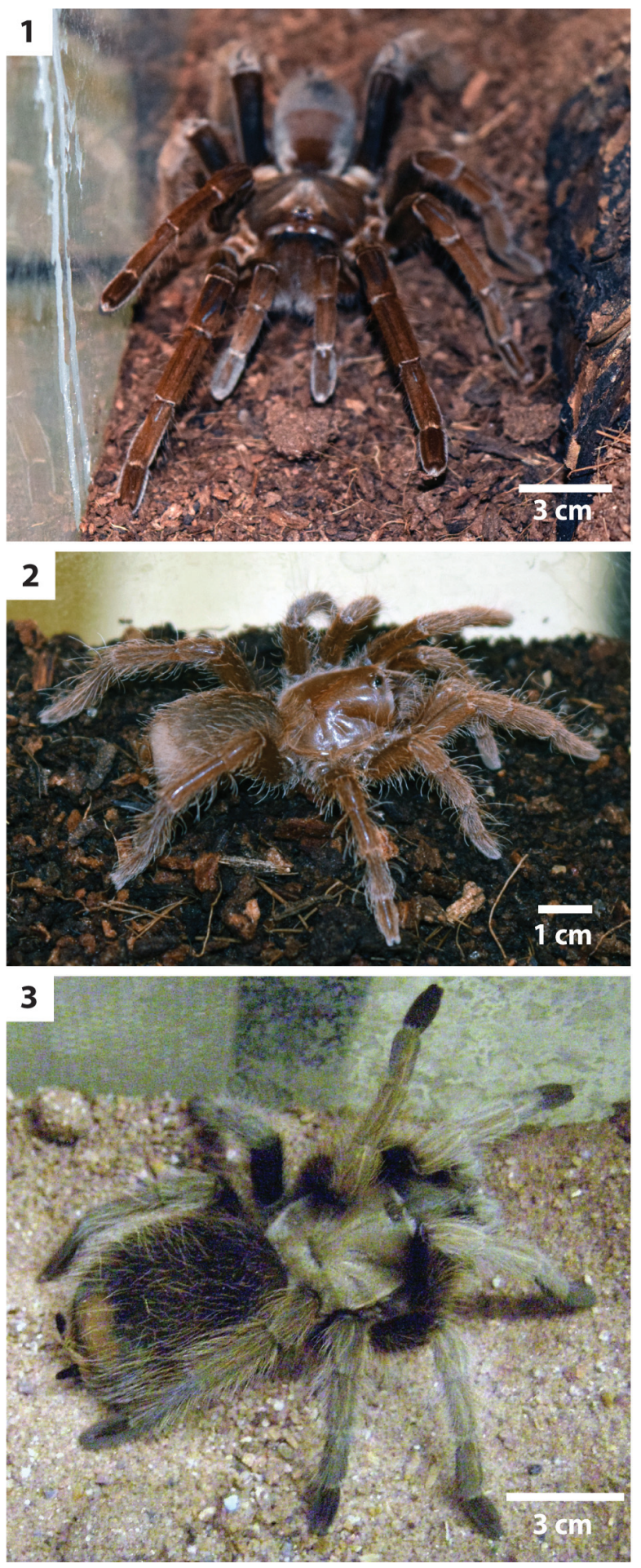

FIGURE 2. Tarantula specimens. 1, Hysterocrates gigas. 2, Pelinobius muticus. 3, Aphonopelma chalcodes.
(Cameroon) (Smith, 1990). It is the largest of the Old World tarantulas with an opisthosoma up to 10 $\mathrm{cm}$ wide and a leg span of up to $20 \mathrm{~cm}$. Hysterocrates gigas ranges in color from dull black and gray to orange and brown (Smith, 1990). Burrows of $H$. gigas have been noted as being deep and intricate, but have not been described in detail. Pelinobius muticus (Figure 2.2) is native to scrublands and grasslands of East Africa (Kenya, Tanzania) (Smith, 1990). It is typically brown to orange in color with a leg span that can reach $20 \mathrm{~cm}$. Aphonopelma chalcodes (Figure 2.3) is common in the semiarid deserts of the southwestern United States (Arizona) and northern Mexico (Marshall, 1996). It is a large-bodied spider, 8-13 cm long, with uniform tan-colored hairs. Burrows of $A$. chalcodes have been described as being simple with large diameter openings (Marshall, 1996; Hils and Hembree, 2015). All three species are active, nocturnal predators that feed primarily on insects and other spiders, but also on small reptiles and rodents, and even birds (Marshall, 1996).

Eight individuals of each species were obtained from commercial sources. All specimens of Hysterocrates and Aphonopelma were adults, whereas specimens of Pelinobius were juveniles (Table 1). This difference was a result of lack of availability of adult specimens of Pelinobius. Each species was represented by both males and females, but not in equal numbers. The spiders were acclimated to laboratory conditions for a minimum of two weeks prior to the start of burrowing experiments. During this time the spiders were housed in sediment-filled, 10 gal ( $38 \mathrm{~L})$ terraria. The laboratory was kept on a 12-hour light cycle with temperatures between $25-30{ }^{\circ} \mathrm{C}$ and humidity at $\sim 35 \%( \pm 5 \%)$. The moisture of the burrowing media was maintained by regular spraying of water both during the acclimation period and the experiments. The three species were fed live crickets weekly; any dead crickets were removed from the terraria. Direct handling of the spiders was minimized to avoid altering their behavior and to avoid additional stress.

Three sizes of terraria were used in the experiments: 30 gallon $(114 \mathrm{~L})(90 \mathrm{~L} \times 42 \mathrm{~W} \times 30 \mathrm{H} \mathrm{cm})$, 56 gallon $(212 \mathrm{~L})(75 \mathrm{~L} \times 45 \mathrm{~W} \times 65 \mathrm{H} \mathrm{cm})$, and 65 gallon $(246 \mathrm{~L})(91 \mathrm{~L} \times 45 \mathrm{~W} \times 62 \mathrm{H} \mathrm{cm})$, filled with sediment to depths of 35,50 , and $55 \mathrm{~cm}$, respectively (Table 2). The terraria used for each species were based on the mean size of the individuals. Different sized terraria were used to evaluate the effects of space constraints on animal behavior and the morphology of burrows produced by the 
TABLE 1. Tarantula species studied in these experiments, numbers of individuals involved (F/M = females $/ \mathrm{males}$ ), range of lengths of the specimens, the environments and geographic locations that the tarantulas inhabit.

\begin{tabular}{lcccc}
\hline \multicolumn{1}{c}{ Species } & $\begin{array}{c}\# \\
\text { Individuals } \\
\text { (F/M) }\end{array}$ & $\begin{array}{c}\text { Length } \\
\mathbf{( c m )}\end{array}$ & Environment & Location \\
\hline Hysterocrates gigas & $5 / 3$ & 6 & Subtropical to tropical forests & West Africa \\
Pelinobius muticus & $6 / 2$ & 2 & Scrublands and grasslands & East Africa \\
Aphonopelma chalcodes & $5 / 3$ & 5 & Semi-arid desert & Western North America \\
\hline
\end{tabular}

TABLE 2. Experimental parameters used for each tarantula species including terrarium size (in liters), sediment content and depth (in $\mathrm{cm}$ ), air temperature, and sediment moisture. Sediment components include organic matter (OM), clay $(\mathrm{CL})$, and sand $(\mathrm{SA})$.

\begin{tabular}{lccccc}
\hline \multicolumn{1}{c}{ Species } & $\begin{array}{c}\text { Terrarium Size } \\
\text { (L) }\end{array}$ & Sediment & $\begin{array}{c}\text { Sediment } \\
\text { Depth }(\mathbf{c m})\end{array}$ & $\begin{array}{c}\text { Temperature } \\
\left({ }^{\circ} \mathbf{C}\right)\end{array}$ & $\begin{array}{c}\text { Moisture } \\
(\%)\end{array}$ \\
\hline Hysterocrates gigas & $114,212,246$ & $\mathrm{OM}, \mathrm{CL}$ & $35,50,55$ & $25-32$ & 60 \\
Pelinobius muticus & $114,212,246$ & $\mathrm{OM}, \mathrm{CL}$ & $35,50,55$ & $25-30$ & 40 \\
Aphonopelma chalcodes & $114,212,246$ & $\mathrm{CL}, \mathrm{SA}$ & $35,50,55$ & $25-32$ & 20 \\
\hline
\end{tabular}

spiders. Heat lamps were used to increase the temperature in each enclosure to that of the natural environment of each species. Sediment used to fill the terraria were varying mixtures of finely shredded coconut fiber (organic material), fine- to medium-grained quartz sand, and sifted potting soil (silt and clay) based on the soil composition required for each species (Table 2) (Marshall, 1996). Sediment mixtures were homogenized and moistened prior to filling the terraria. Sediment density and moisture were measured using a Field Scout SC900 Soil Compaction Meter (Spectrum Technologies Inc.) and an Aquaterr EC-300 Salinity Multimeter, respectively. The sediment surface in each terrarium was smoothed before the introduction of the tarantula in order to assess the level of surface modification.

A single tarantula was placed in each experimental terrarium (Figure 3). The tarantulas were left in the terraria for three to 12 months before their removal. The tarantulas were observed, photographed, and digitally recorded before, during, and after burrowing. Observations were made three to five times per day at the start of each experiment and then once per day once the tarantulas had constructed burrows. Observations included the time taken before the tarantulas started burrowing, burrowing techniques used, time required to construct the burrow, production of surface structures, and behaviors associated with the burrow. At the end of each experimental period, the tarantulas were removed from the terrarium when they came to the surface to feed or were lured out of their burrows. Once the tarantula was removed, the open burrows were filled with Drystone $\AA$ plaster. The resulting burrow casts were excavated and described.

Descriptions of the three-dimensional burrow casts included qualitative and quantitative properties related to architectural and surficial morphology (Figure 4). Architectural morphology is defined by the burrow's general appearance, dimensions, cross-sectional shape, orientation, type and amount of branching, and degree of interconnectedness between different burrow elements (Bertling et al., 2006). Surficial morphology includes structures such as scratches, bumps, and linings on the burrow walls that record burrow construction and maintenance techniques, as well as the locomotion styles. Each burrow cast was described with eight quantitative measurements: 1) maximum depth; 2) total length; 3) tunnel or shaft width and height measured every $1 \mathrm{~cm}$; 4) ratio of cross-sectional width to height; 6) tunnel or shaft circumference measured every $1 \mathrm{~cm}$; 7) slope of shafts or tunnel with respect to the horizontal; and 8) angle of branching if present (Figure 4.1). Measurements of tunnel and shaft width, height, circumference, and slope for each burrow were combined to produce a maximum, minimum, and mean value for each property. Cross-sectional width to height ratio was calculated with the mean values of the burrow. Burrow complexity and tortuosity are semi-quantitative descriptions of burrow morphology which are scale independent (e.g., Meadows 1991; Hembree and Hasiotis, 2006). 

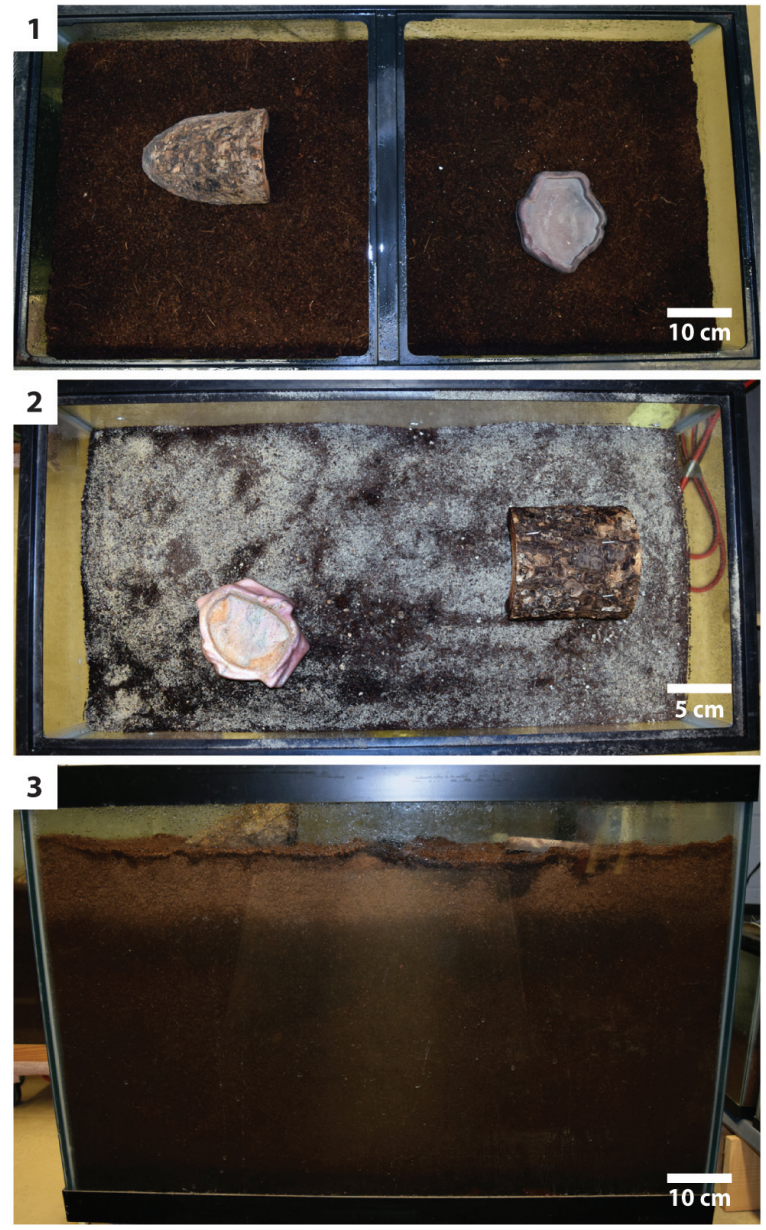

FIGURE 3. Examples of sediment-filled terraria. 1, Surface of terrarium surface of for Hysterocrates gigas. 2, Surface of terrarium substrate for Aphonopelma chalcodes. 3, Side view of a $246 \mathrm{~L}$ terrarium housing $H$. gigas.

Complexity is the sum of the number of different tunnels, shafts, surface openings, and chambers in a burrow system (Figure 4.2). Tortuosity is a measure of the deviation of the morphology of the shafts and tunnels from a straight line (Figure 4.3). Tortuosity is calculated by dividing the total length a shaft or tunnel by the straight-line distance between the two ends. The tortuosity of the entire burrow system is determined by calculating the average tortuosity of all of the burrow segments.

Quantitative properties were used to statistically compare the tarantula burrow casts. All statistical analyses were performed using PAST (ver. 2.17b) (Hammer et al., 2001). The Bray-Curtis similarity measure was used to determine the degree of similarity between the quantitative properties of burrow casts within each species and between the three species of tarantulas. The Bray-Curtis simi- larity measure is a nonparametric statistical analysis in which the sum of the differences for each quantitative measurement is divided by the sum of the total measurements in the sample (Bray and Curtis, 1957). This number is subtracted from 1.0 to determine similarity. Similarity is ranked from 0.0 (completely dissimilar) to 1.0 (identical). Two burrows with a rank of 1.0 were considered identical, ranks between 0.9 and 0.6 express high to moderate similarity, and ranks $\leq 0.5$ are dissimilar (c.f., Hembree et al., 2012; Hembree, 2013, 2014; Catena and Hembree, 2014; Dzenowski and Hembree, 2014; Bowen and Hembree, 2014). Bray Curtis similarity scores were used to construct dendrograms of similarity. The dendrograms indicate the level of similarity between burrows with different qualitative architectures and those produced by different animals. The nonparametric Mann-Whitney and Kolmogorov-Smirnov tests were used to evaluate the differences in the 18 quantitative properties between the tarantula burrows. The tests were used to determine which of the quantitative burrow properties of the different trace makers were distinct.

The tarantula burrows were then compared to burrows produced by four other burrowing animals from previous studies which were measured and described in the same manner. These trace makers included: the trapdoor spider Gorgyrella inermis (Arachnida: Araneae) (Hils and Hembree, 2015), the scorpion, Pandinus imperator (Scorpiones: Scorpionidae) (Hembree, 2014), the salamander Ambystoma tigrinum (Amphibia: Caudata) (Dzenowski and Hembree, 2014), and the skink, Mabuya multifasciata (Squamata: Scincidae) (Catena and Hembree, 2014) (Figure 5). These four species were selected for this comparison because they exhibit similar burrow-related behaviors, inhabit similar environments and substrates, and produce several different burrow architectures that are similar to those of the tarantulas. For each trace maker, a set of burrows casts equivalent in number (7-9) and architecture to those of the tarantulas was selected.

\section{RESULTS}

\section{Behaviors and Burrowing Techniques}

The tarantulas started to excavate burrows 0 10 days after the experiments began with a mean duration of two days to begin burrowing. Specimens of Pelinobius burrowed the fastest among the three species, typically constructing burrows within one hour of being placed in the terraria. Aph- 


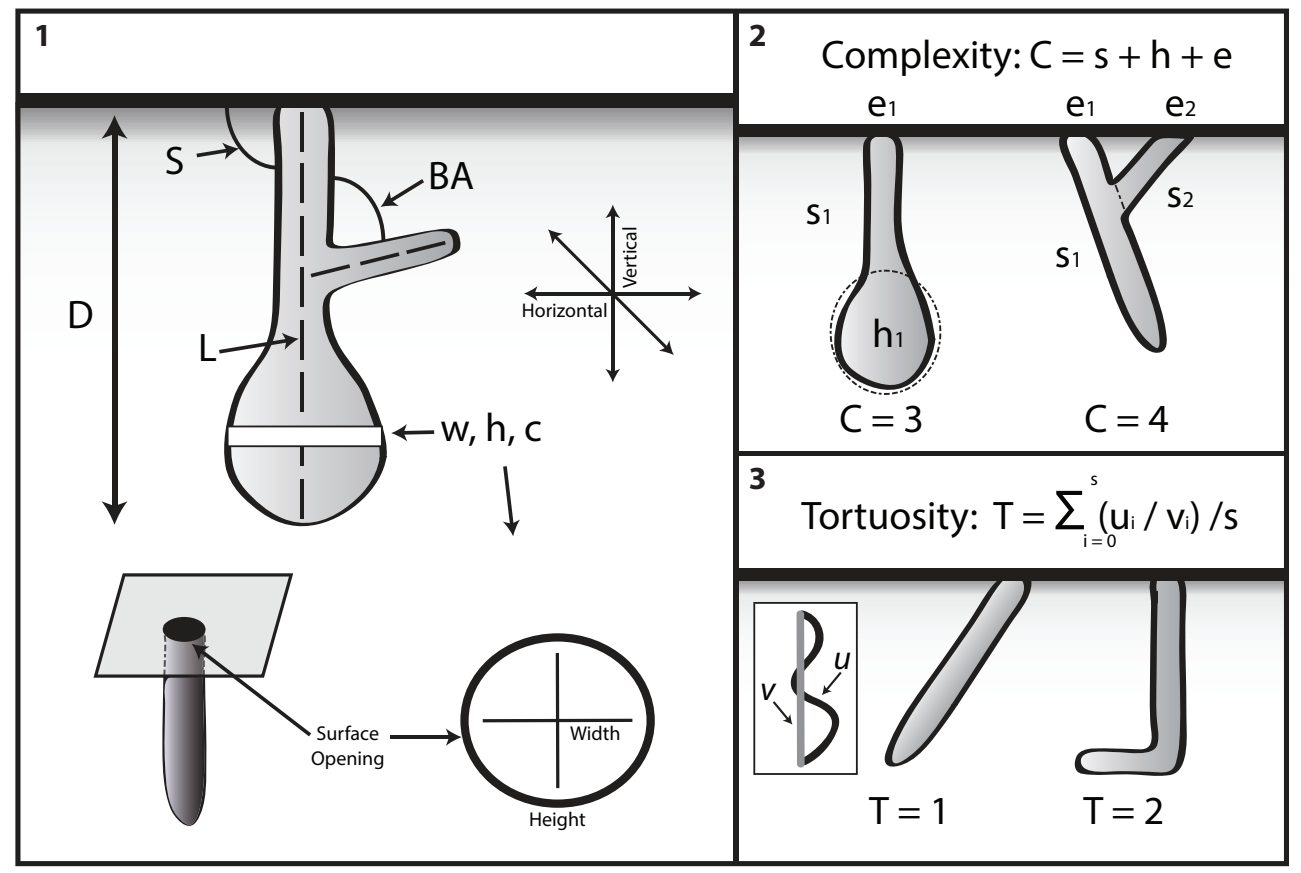

FIGURE 4. Quantitative burrow property diagram. 1, Burrows were described by their slope (S), maximum depth (D), tunnel, shaft, and chamber width $(w)$, height $(h)$, and circumference (c), total length (L), and branching angle (BA). 2 , Complexity is the sum of the number of segments (s), chambers (h), and surface openings (e) within a single burrow system. 3, Tortuosity is the average sinuosity of the segments within a burrow system. The tortuosity of a single segment is found by dividing the total length ( $u$ ) by the straight line distance (v). Modified from Hils and Hembree (2015).

onopelma burrowed the slowest, taking 6-8 days to begin burrow construction. Burrows were located in many different places on the sediment surface, but the tarantulas often constructed burrows along the walls of the terrarium or near water dishes, log hides, and stones.

Individuals of Hysterocrates gigas and Aphonopelma chalcodes began constructing their burrows through direct excavation using their pedipalps and chelicerae (Figure 6.1-2; Appendix 1). Excavated sediment was carried a short distance $(1-15 \mathrm{~cm})$ from the burrow opening and deposited. This technique was continued throughout the construction and maintenance of the burrow; however, the distance the excavated sediment was transported became shorter as the burrow deepened. As a result of their sandy substrate, specimens of Aphonopelma often started three to four failed burrows that collapsed during construction. When this happened the tarantula moved to a new location in the terrarium to start a new burrow. Neither $H$. gigas nor $A$. chalcodes used a large amount of silk in their burrows, but thin layers were placed on the walls of the upper portion of the shaft or tunnel as well as around the sediment surface immediately adjacent to the burrow opening. Thin layers of silk were intermittently placed over the burrow opening.

Individuals of Pelinobius began burrow construction by forcing themselves into the upper 1-3 $\mathrm{cm}$ of sediment (Appendix 2). Once below the sediment surface, Pelinobius began to construct an open shaft by excavating sediment using their pedipalps and chelicerae (Figure 6.3-4). This sediment was not carried to the surface, but was instead packed upward from below to form a sediment mound above the developing burrow. Pelinobius applied thin layers of silk to the burrow walls along its entire length.

The burrows of all three species of tarantulas were used for dwelling and as sites for ambush predation. Specimens of Hysterocrates and Pelinobius were only observed inside their burrows if some portion was constructed along the terrarium wall or if they were present just below the burrow opening (Figure 6.5-6). This occurred in approximately $60 \%$ of the experiments. Specimens of Aphonopelma typically stayed in their burrows as well, but did exit their burrows regularly to actively hunt, primarily during dark hours. All three species engaged in ambush predation, and Hysterocrates and Pelinobius seemed to obtain prey exclusively through this method. The tarantulas waited just 

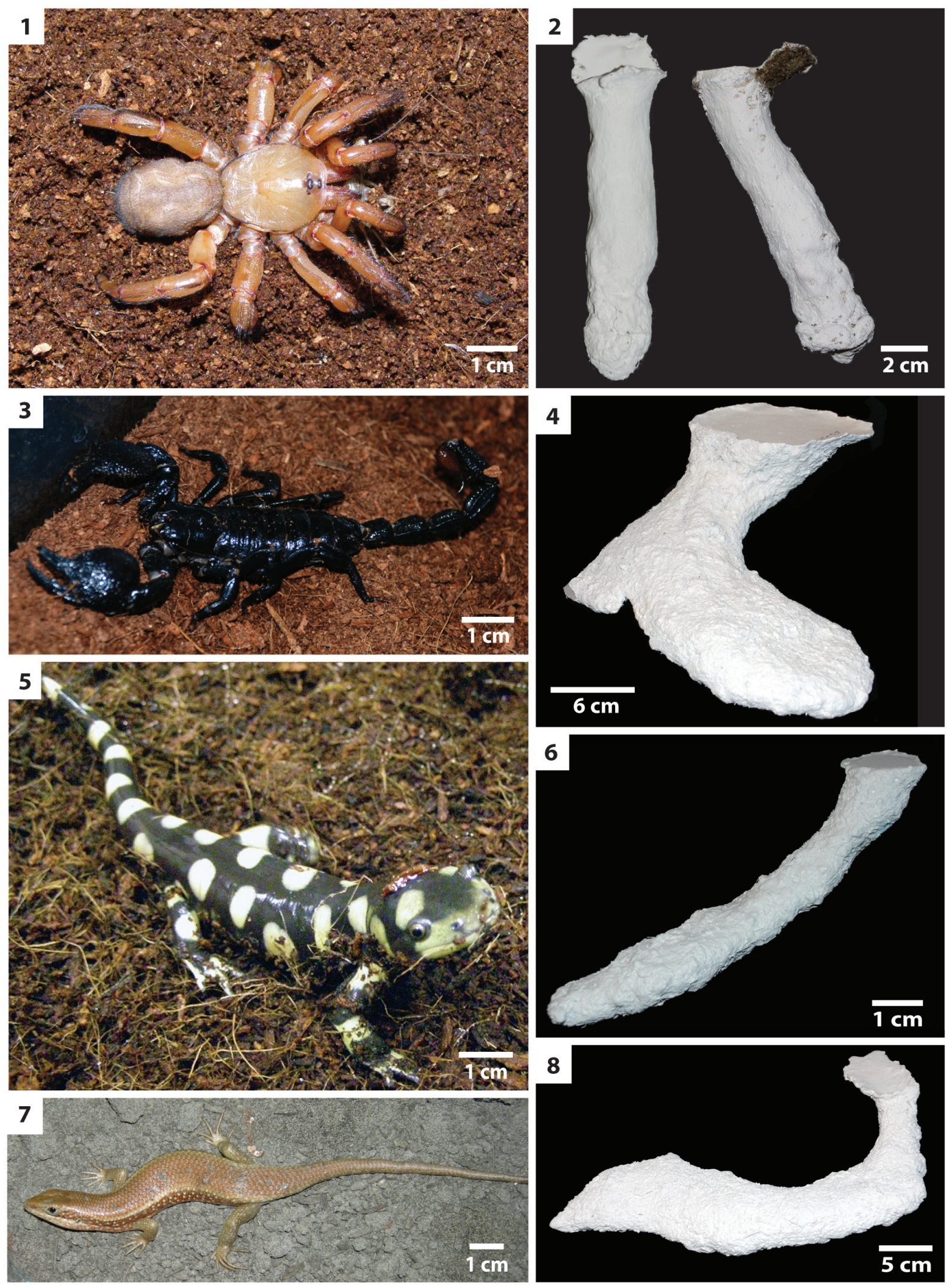

FIGURE 5. Comparative trace-making animals and casts of their typical burrow morphologies. 1-2, Gorgyrella sp. (trapdoor spider). 3-4, Pandinus imperator (scorpion). 5-6, Ambystoma tigrinum (salamander). 7-8, Mabuya multifasciata (skink). 

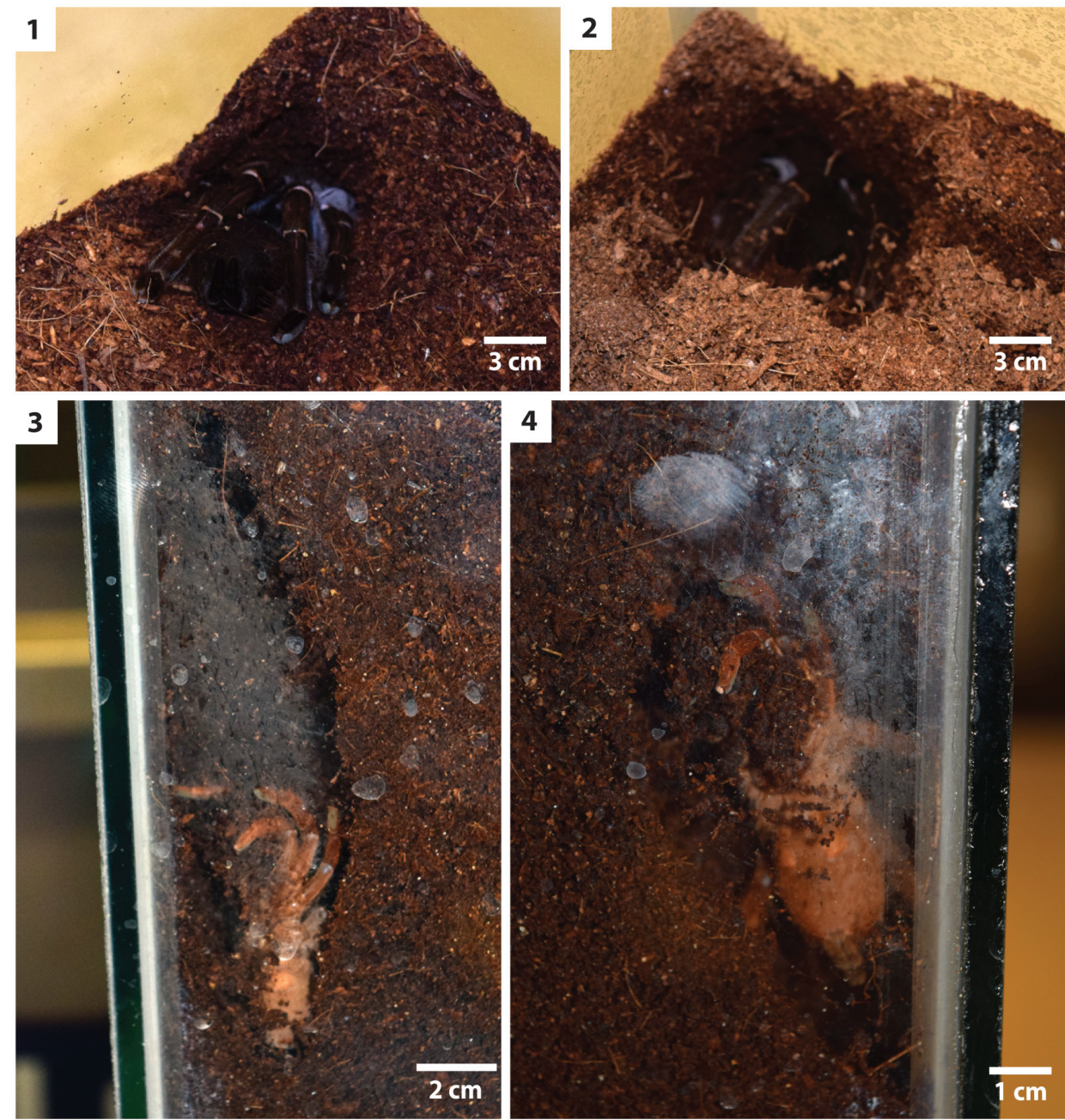

5
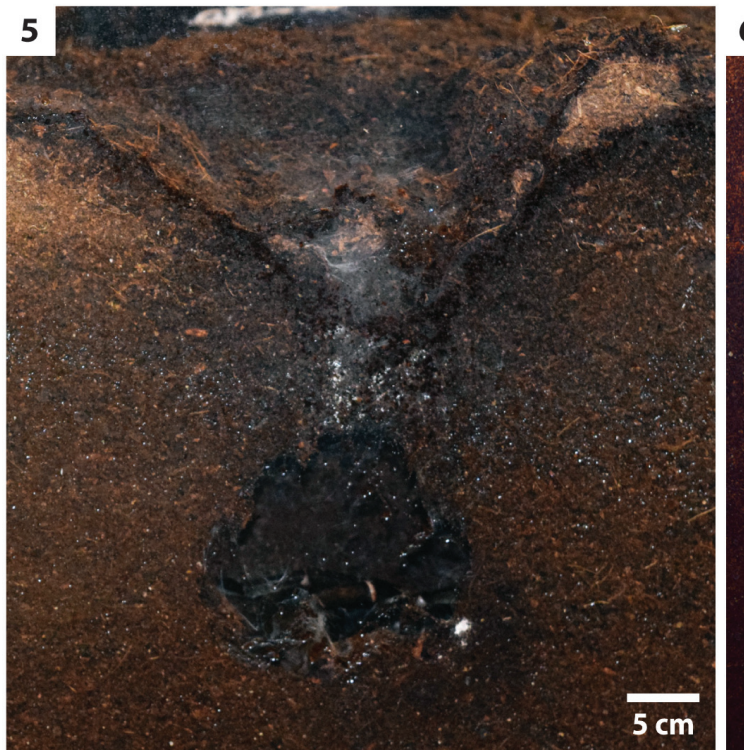

6

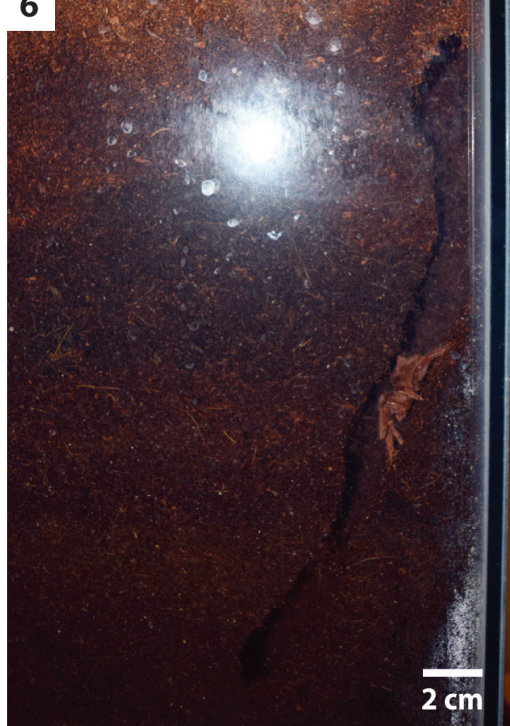

FIGURE 6. 1, Specimen of Hysterocrates gigas initiating burrow construction. 2, Continued excavation of $H$. gigas burrow; sediment from burrow is deposited on the surface behind the burrow opening. 3 , Specimen of Pelinobius muticus transporting excavated sediment with its pedipalps up the burrow shaft. 4, Specimen of $P$. muticus packing excavating sediment into the base of the sediment mound at the top of the burrow shaft. 5, Specimen of $H$. gigas in its burrow chamber. 6, Specimen of $P$. muticus in burrow shaft below the burrow opening. 
below the opening of their burrow and grabbed prey animals that moved near the entrance with their pedipalps, dragging them into the burrow for consumption. The burrows, once constructed, were occupied by the tarantulas during the entire experimental period of three to 12 months.

\section{Surface Morphology}

Pelinobius only modified the sediment surface immediately above their burrow. They produced low (1-4 cm) mounds of sediment above their burrows, which were $4-5 \mathrm{~cm}$ in diameter (Figure 7.1). These mounds were formed as Pelinobius forced excavated sediment upward. Hysterocrates altered more of the substrate surface, producing large (5$10 \mathrm{~cm}$ diameter) sediment mounds around their burrow opening, some up to $10 \mathrm{~cm}$ above the substrate surface (Figure 7.2). Hysterocrates also deposited elongate, $1-2 \mathrm{~cm}$ thick piles of excavated sediment extending up to $15 \mathrm{~cm}$ away from the burrow opening (Figure 7.3). Aphonopelma had the greatest effect on the sediment surface. They produced 1-2 $\mathrm{cm}$ thick spoil piles of excavated sediment and, in the process of burrowing in their sandy substrate, produced an undulatory topography as several burrows were begun and collapsed (Figure 7.4). The effect was differences in relief of up to $10 \mathrm{~cm}$ along the sediment surface.

\section{Burrow Morphology}

Hysterocrates gigas. Hysterocrates gigas constructed burrows in cohesive, moist substrates. Burrows of $H$. gigas $(n=9)$ consisted of a single circular surface opening leading to a short (1-3 $\mathrm{cm}$ ) vertical shaft with a circular cross section connected to an elongate, irregularly ovoid chamber, which was up to twice the size of the spider (Figure 8; Table 3). The chamber was positioned at either the top or bottom of the burrow, or both. Over extended periods of occupation, an elongate shaft extending downward from the chamber was constructed leading deep $(>20 \mathrm{~cm})$ into the substrate. This shaft could then turn horizontally to become an elongate tunnel. An additional, laterally expanded chamber may also have been produced along the burrow's length.

Pelinobius muticus. Pelinobius muticus constructed burrows in cohesive, moist to dry substrates. Burrows of $P$. muticus ( $\mathrm{n}=8$ ) consisted of a single circular surface connection, normally sealed with a thin layer of excavated sediment and silk, leading to a sinuous, vertical shaft with a circular to elliptical cross section that sometimes possessed multiple branches (Figure 9; Table 3).
Laterally expanded chambers were present at the lowermost portion of the burrow and at branch points. Chambers were 1.5 times as large as the spider.

Aphonopelma chalcodes. Aphonopelma chalcodes constructed burrows in cohesive to loose, dry substrates. Burrows of $A$. chalcodes $(n=9)$ consisted of a single, elliptical surface opening leading to either a simple, subvertical tunnel with an elliptical cross section or a helical, subvertical tunnel with an elliptical cross section (Figure 10; Table 3). Some of the tunnels ended in laterally and vertically expanded chambers up to twice the size of the spider. Series of elongate, paired parallel ridges were preserved on some casts, produced by the pedipalps during excavation (Figure 10.1, 10.7). Each ridge was $1-3 \mathrm{~mm}$ wide and $1-4 \mathrm{~mm}$ high.

\section{Burrow Analyses}

Comparison of tarantula burrows. Burrows of Hysterocrates gigas, Pelinobius muticus, and Aphonopelma chalcodes sort into four moderately to highly similar $(B C>0.7)$ clusters according to their trace maker and general architecture (Figure 11). Three of the clusters $(A-C)$ are composed of mostly $(73-100 \%)$ the burrows of one tarantula. Cluster A consists of five of the eight burrows of Aphonopelma chalcodes with a similarity of 0.72 0.89 . These burrows are relatively short and shallow, subhorizontal tunnels, mostly lacking terminal chambers. Cluster B consists of five of the 10 burrows of Hysterocrates gigas as well as one burrow of $A$. chalcodes with a similarity of $0.87-0.95$. These burrows include relatively short and shallow, vertical shafts with large chambers near the burrow opening. Cluster $\mathrm{C}$ consists of all eight burrows of Pelinobius muticus and three burrows of $H$. gigas with a similarity of $0.83-0.95$. These burrows are sinuous, elongate and deep, vertical shafts with one or more slightly enlarged chambers along the length of the burrow. Cluster $D$ consists of two burrows of both $H$. gigas and $A$. chalcodes with a similarity of $0.86-0.92$. These burrows consist of elongate subvertical tunnels with laterally expanded tunnels. A single burrow of $A$. chalcodes lies outside of all four clusters, splitting off from Clusters $B-D$ at a similarity of 0.67 . This burrow is a large diameter elongate, helical tunnel with an expanded terminal chamber.

Burrows of Hysterocrates gigas and Aphonopelma chalcodes have the most similar quantitative properties of the three tarantulas as assessed by the Mann-Whitney and Kolmogorov-Smirnov 

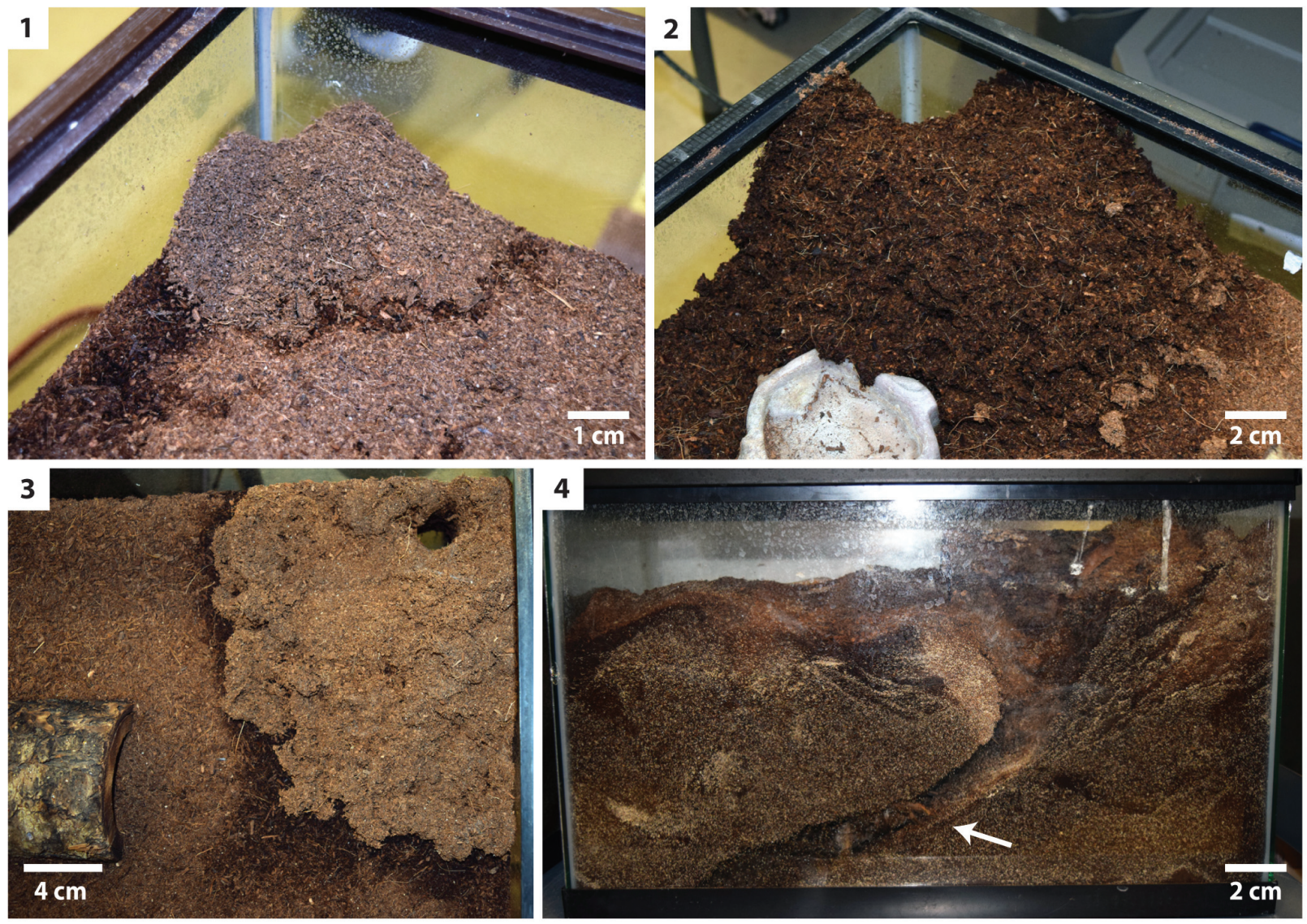

FIGURE 7. 1, Low mound of excavated sediment produced by Pelinobius muticus; circular opening is present in the center. 2, Large mound of excavated sediment produced by Hysterocrates gigas with a circular opening in the center of the mound. 3, Extensive spoil pile of excavated sediment extending from the opening of a $H$. gigas burrow. 4, Side view of an Aphonopelma chalcodes terrarium showing extensive, irregular surface topography produced by burrow excavation as well as the exposed cross section of a helical burrow (at arrow).

tests; only five of 18 properties are significantly different (Appendix 3). Burrows of $H$. gigas have greater maximum depth, maximum circumference, maximum slope, mean slope, and complexity in comparison to burrows of $A$. chalcodes. In comparison to Pelinobius muticus, however, burrows of $H$. gigas have greater width, height, circumference (max, min, and mean of each), and minimum slope (10 of 18 properties) (Appendix 3). Burrows of $A$. chalcodes and $P$. muticus are more variable in their differences; $A$. chalcodes has a greater width, mean height, mean circumference, and minimum slope, whereas $P$. muticus has a greater depth, total length, maximum and mean slope, complexity, and tortuosity (12 of 18 properties) (Appendix 3 ).

Comparison with burrows of other animals. The burrows of the three tarantula species were compared to those of four other animals using the same set of quantitative properties (Appendix 4). The burrows of the seven animals sort into 11 highly similar $(\mathrm{BC}>0.80)$ clusters, each composed largely $(80-100 \%)$ of the burrows of a single trace maker with the exception of one cluster composed of equal numbers of burrows of Hysterocrates gigas and Aphonopelma chalcodes (I) (Figure 12). Cluster $A$ is composed entirely of the nine burrows of the scorpion Pandinus imperator ( $\mathrm{BC}>0.80$ ). Cluster $B$ is composed four of the nine burrows of $A$. chalcodes $(\mathrm{BC}>0.83$ ). Clusters $\mathrm{C}$ and $\mathrm{E}$ are composed of six and two of the burrows of the skink Mabuya multifasciata (BC >0.82, 0.91). Clusters $D$ and $F$ are each composed of four of the burrows of the salamander Ambystoma tigrinum ( $B C>0.90,0.89$ ). Cluster $G$ is composed of four of the 10 burrows of $H$. gigas as well as one burrow of A. chalcodes (BC>0.88). Cluster $\mathrm{H}$ is composed of all seven of the burrows of Gorgyrella inermis as well as one burrow of $H$. gigas $(B C>0.93)$. Cluster $\mathrm{I}$ is composed of two burrows each of $H$. gigas and A. chalcodes $(\mathrm{BC}>0.86)$. Cluster $\mathrm{J}$ is composed of 

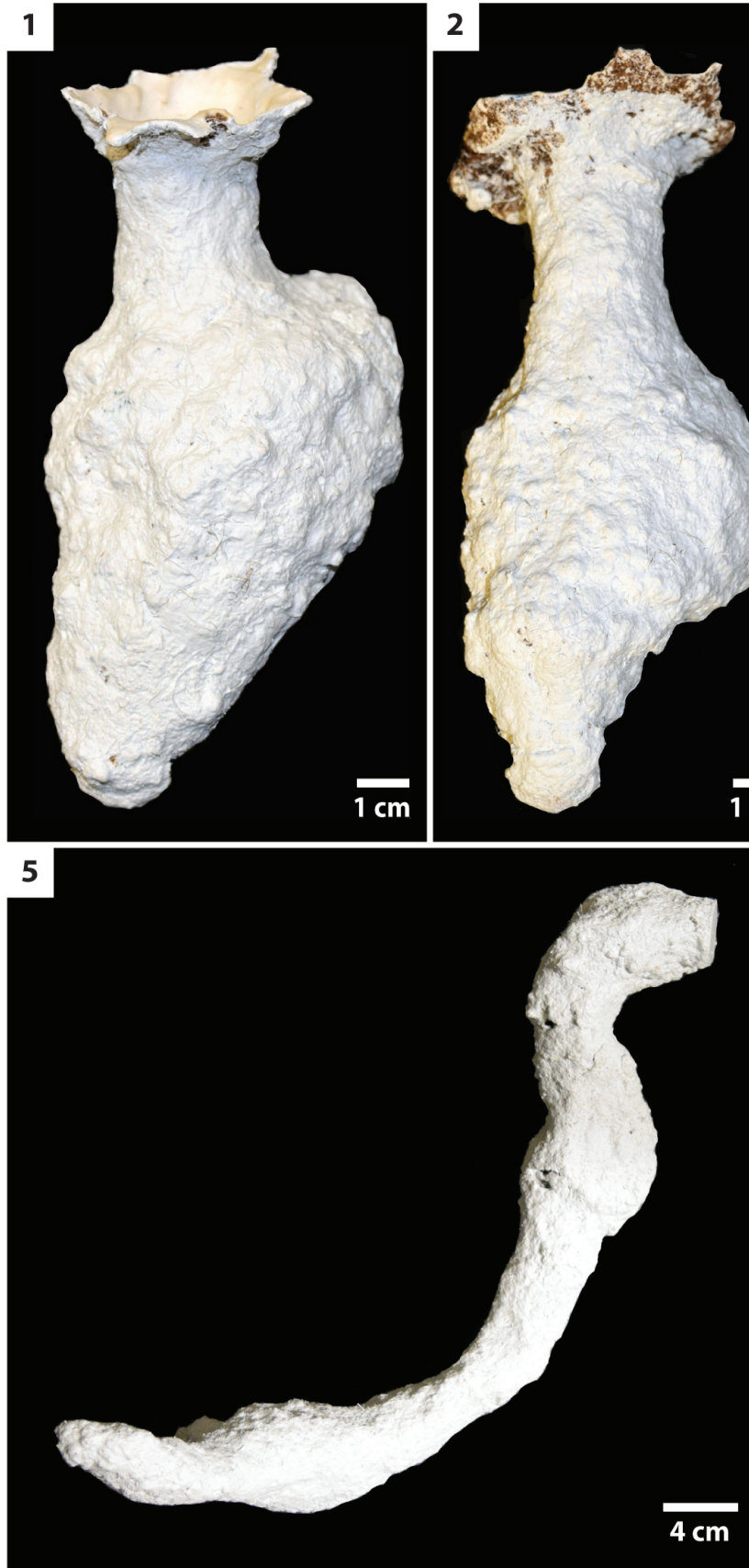

2

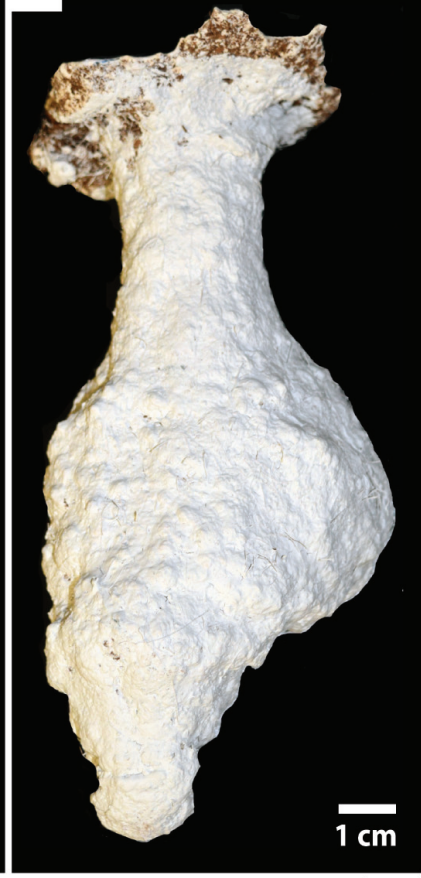

3

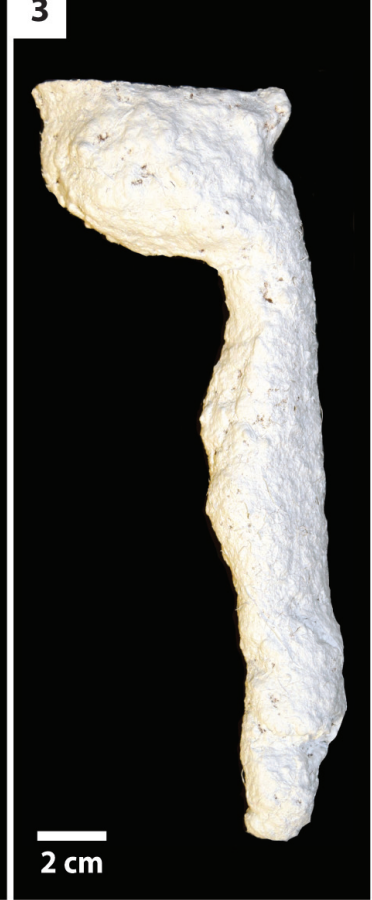

4

4

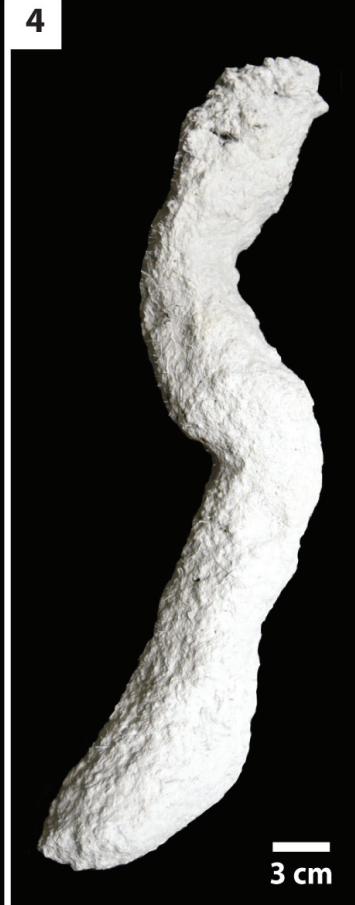

6

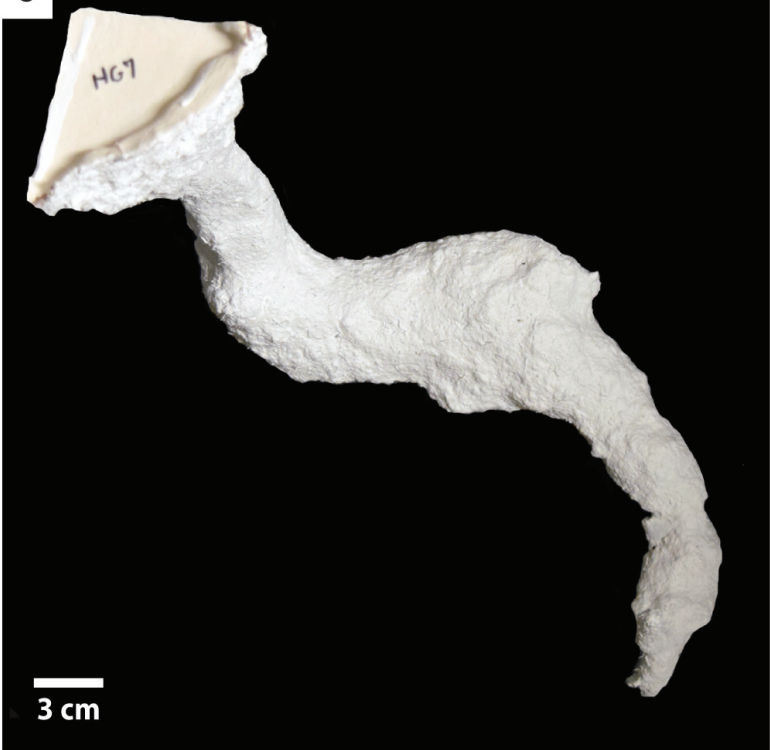

FIGURE 8. Hysterocrates gigas burrow casts. 1, Side view of vertical burrow with expanded terminal chamber (HG4).

2, Side view of vertical burrow with expanded terminal chamber and a short lower shaft (HG2). 3, Side view of a vertical burrow with and expanded upper chamber and an elongate lower shaft. 4, Side view of a sinuous vertical burrow with an upper and terminal expanded chambers (HG8). 5, Side view of a vertical to horizontal burrow with upper and lower expanded chambers (HG9). 6, Top view of a vertical to horizontal burrow with upper and lower expanded chambers (HG7).

two burrows of $H$. gigas $(\mathrm{BC}>0.85)$. Cluster $\mathrm{K}$ is composed of all eight burrows of $P$. muticus and one burrow of $H$. gigas $(\mathrm{BC}>0.87)$.

There is some mixing of burrows of different trace makers within the highly similar clusters, but these only occur among burrows of tarantulas (G, I,
$\mathrm{K}$ ) or tarantulas and trapdoor spiders $(\mathrm{H})$ (Figure 12). In addition, the relative positions of the tarantula burrows in the cluster diagram are not significantly altered by the presence of the additional animal burrows. Most of the burrows produced by tarantulas (22 of 27 ) were present in one moder- 
TABLE 3. Quantitative measurements of tarantula burrows. All measurements in $\mathrm{cm}$ or degrees (slope only); W/H ratio, complexity, and tortuosity are unitless. HG\# = Hysterocrates gigas burrow cast identification number; PM\# = Pelinobius muticus burrow cast identification number; $\mathrm{AC \#}=$ Aphonopelma chalcodes burrow cast identification number.

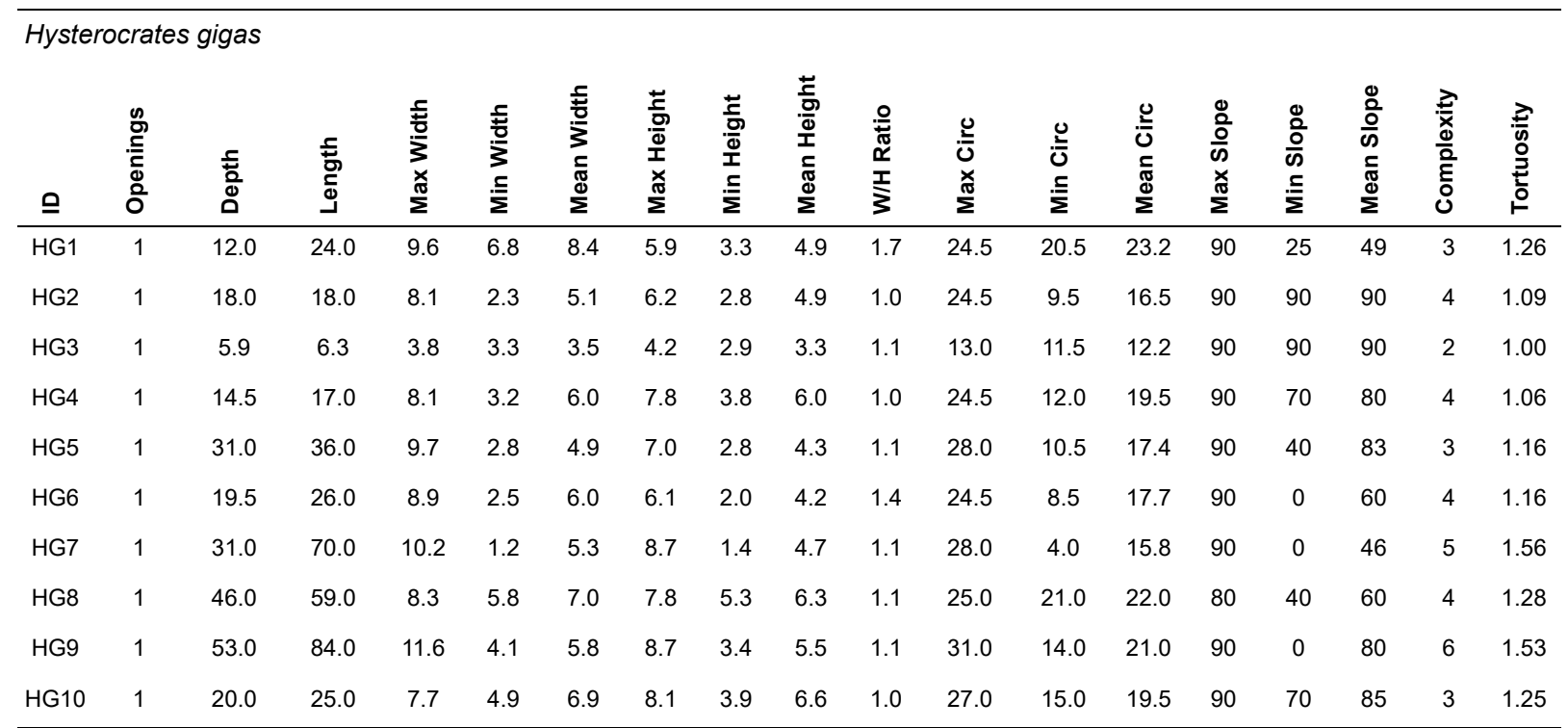

Pelinobius muticus

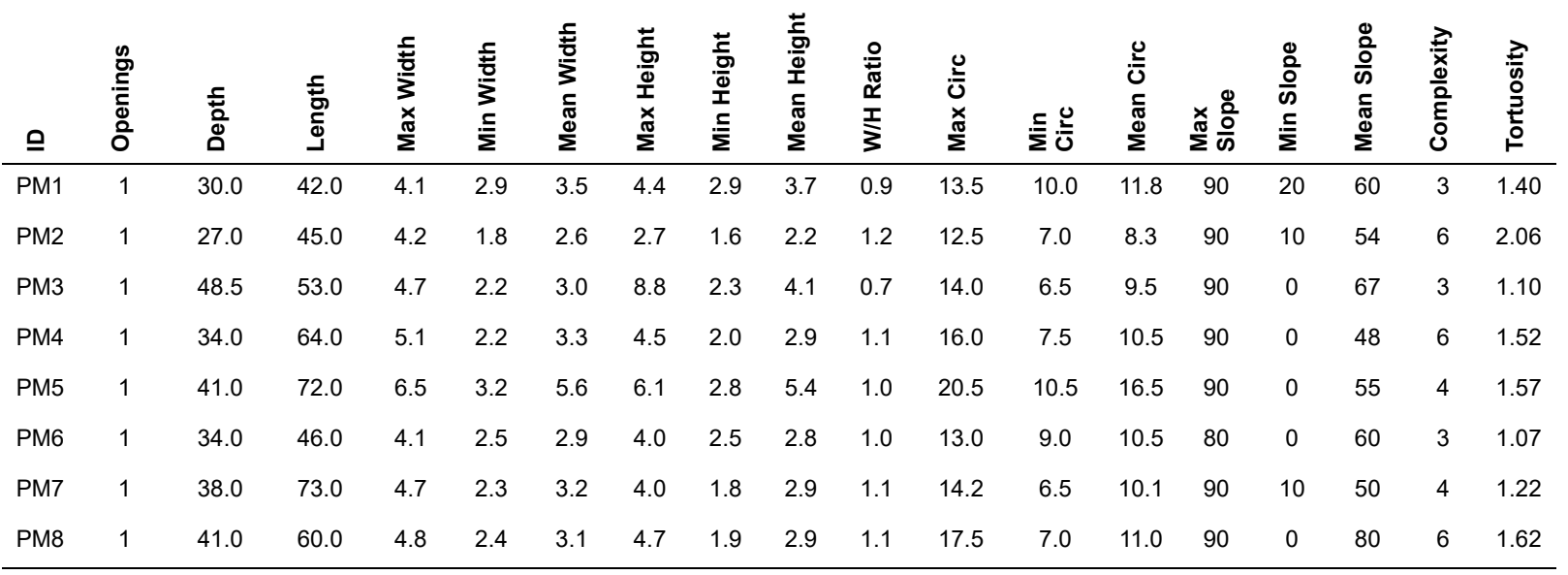

Aphonopelma chalcodes

\begin{tabular}{|c|c|c|c|c|c|c|c|c|c|c|c|c|c|c|c|c|c|c|}
\hline 으 & 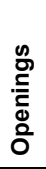 & $\begin{array}{l}\text { 훙 } \\
\text { 口́ }\end{array}$ & 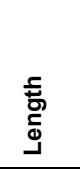 & 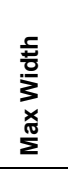 & 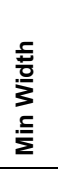 & 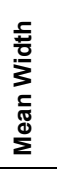 & 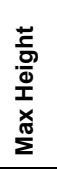 & 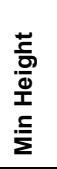 & 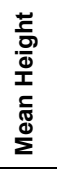 & 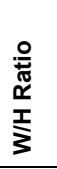 & 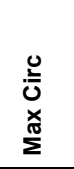 & 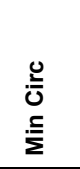 & 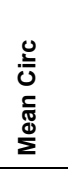 & $\begin{array}{l}\searrow \\
\frac{0}{0} \\
\text { क } \\
\times \\
\Sigma \\
\Sigma\end{array}$ & $\begin{array}{l}\searrow \\
\frac{0}{0} \\
\check{\Sigma} \\
\Sigma\end{array}$ & $\begin{array}{l}₫ \\
\frac{\Xi}{\omega} \\
\frac{0}{\varpi} \\
\Sigma \\
\Sigma\end{array}$ & 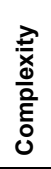 & 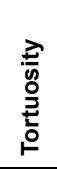 \\
\hline $\mathrm{AC} 1$ & 1 & 9.5 & 17.9 & 7.6 & 3.6 & 6.6 & 6.7 & 2.5 & 5.1 & 0.8 & 22.2 & 11.1 & 19.1 & 55 & 0 & 28 & 2 & 1.04 \\
\hline $\mathrm{AC} 2$ & 1 & 3.1 & 6.1 & 3.7 & 2.9 & 3.4 & 2.4 & 1.2 & 1.9 & 0.5 & 10.9 & 7.1 & 9.5 & 25 & 25 & 25 & 2 & 0.98 \\
\hline AC3 & 1 & 7.5 & 13.5 & 6.0 & 8.3 & 7.9 & 6.1 & 8.2 & 7.0 & 1.0 & 19.2 & 7.4 & 16.6 & 35 & 19 & 25 & 3 & 1.00 \\
\hline $\mathrm{AC} 4$ & 1 & 9.8 & 21.3 & 8.3 & 5.0 & 6.5 & 8.2 & 4.6 & 6.5 & 1.0 & 25.4 & 17.6 & 21.7 & 62 & 21 & 35 & 3 & 1.84 \\
\hline AC5 & 1 & 8.6 & 14.9 & 7.9 & 3.5 & 6.6 & 7.0 & 2.3 & 5.2 & 1.3 & 23.3 & 9.9 & 19.1 & 28 & 21 & 27 & 2 & 1.00 \\
\hline AC6 & 1 & 21.2 & 58.8 & 11.6 & 6.8 & 7.7 & 6.7 & 3.4 & 5.2 & 1.5 & 2.7 & 1.8 & 2.2 & 55 & 17 & 28 & 3 & 2.50 \\
\hline $\mathrm{AC7}$ & 1 & 20.0 & 38.0 & 6.8 & 4.8 & 5.8 & 7.2 & 2.9 & 4.7 & 1.2 & 22.3 & 14.0 & 18.0 & 90 & 0 & 41 & 3 & 1.06 \\
\hline AC8 & 1 & 16.0 & 35.0 & 9.3 & 6.6 & 7.5 & 5.6 & 1.7 & 4.2 & 1.8 & 23.0 & 13.0 & 19.3 & 75 & 40 & 50 & 2 & 1.03 \\
\hline AC9 & 1 & 12.0 & 13.5 & 8.8 & 5.1 & 7.1 & 6.4 & 2.1 & 3.9 & 1.8 & 25.0 & 9.5 & 18.7 & 90 & 60 & 77 & 2 & 1.04 \\
\hline
\end{tabular}




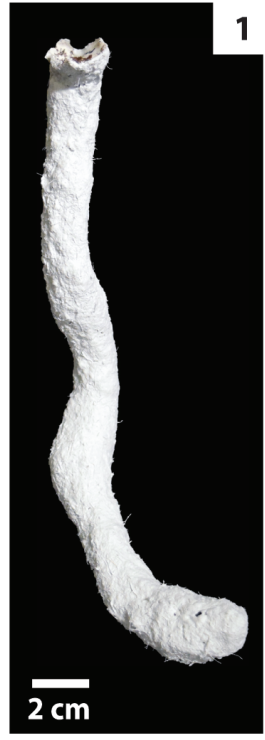

\section{5}
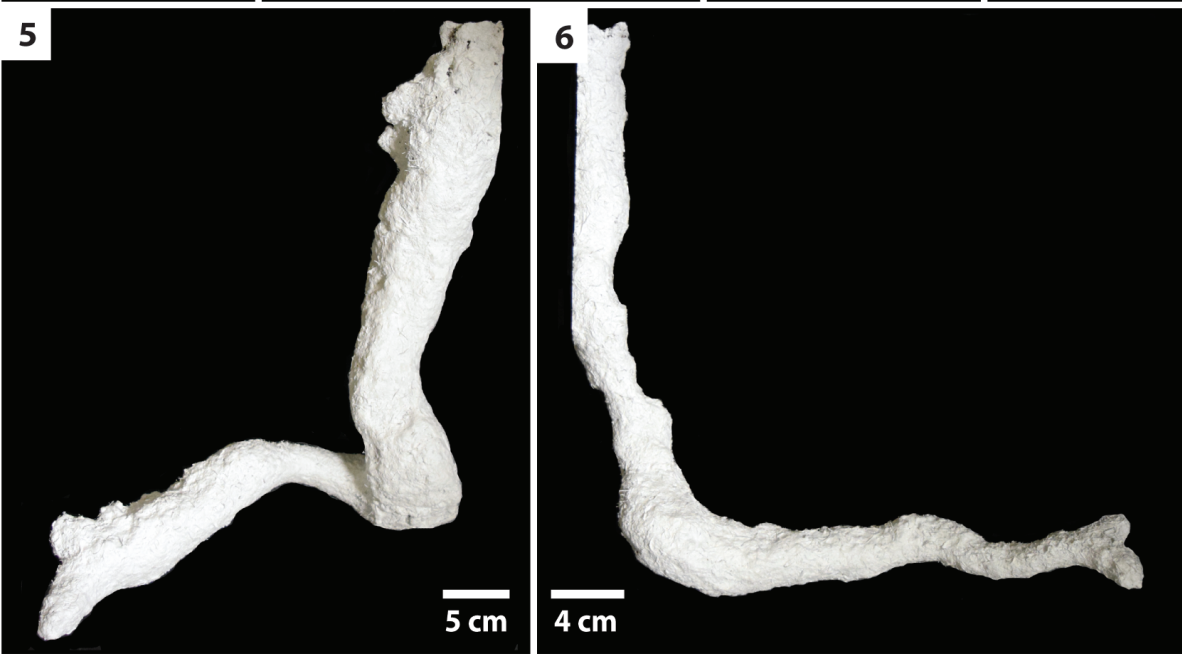

2

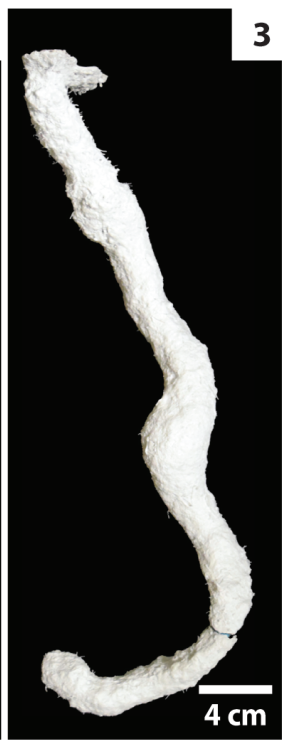

3

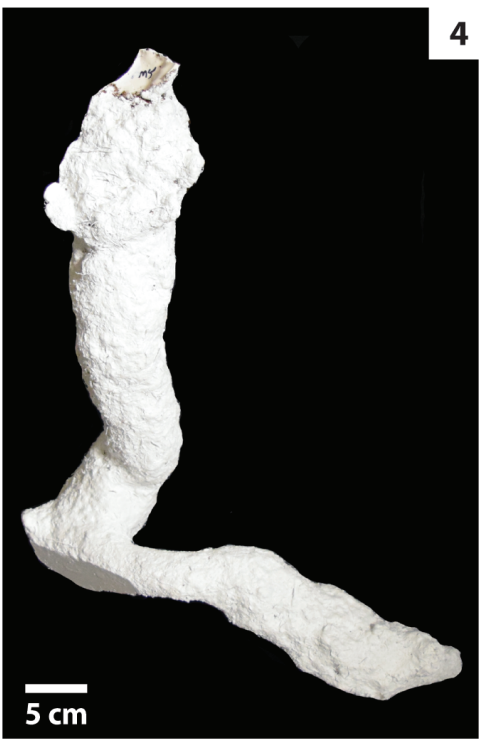

7
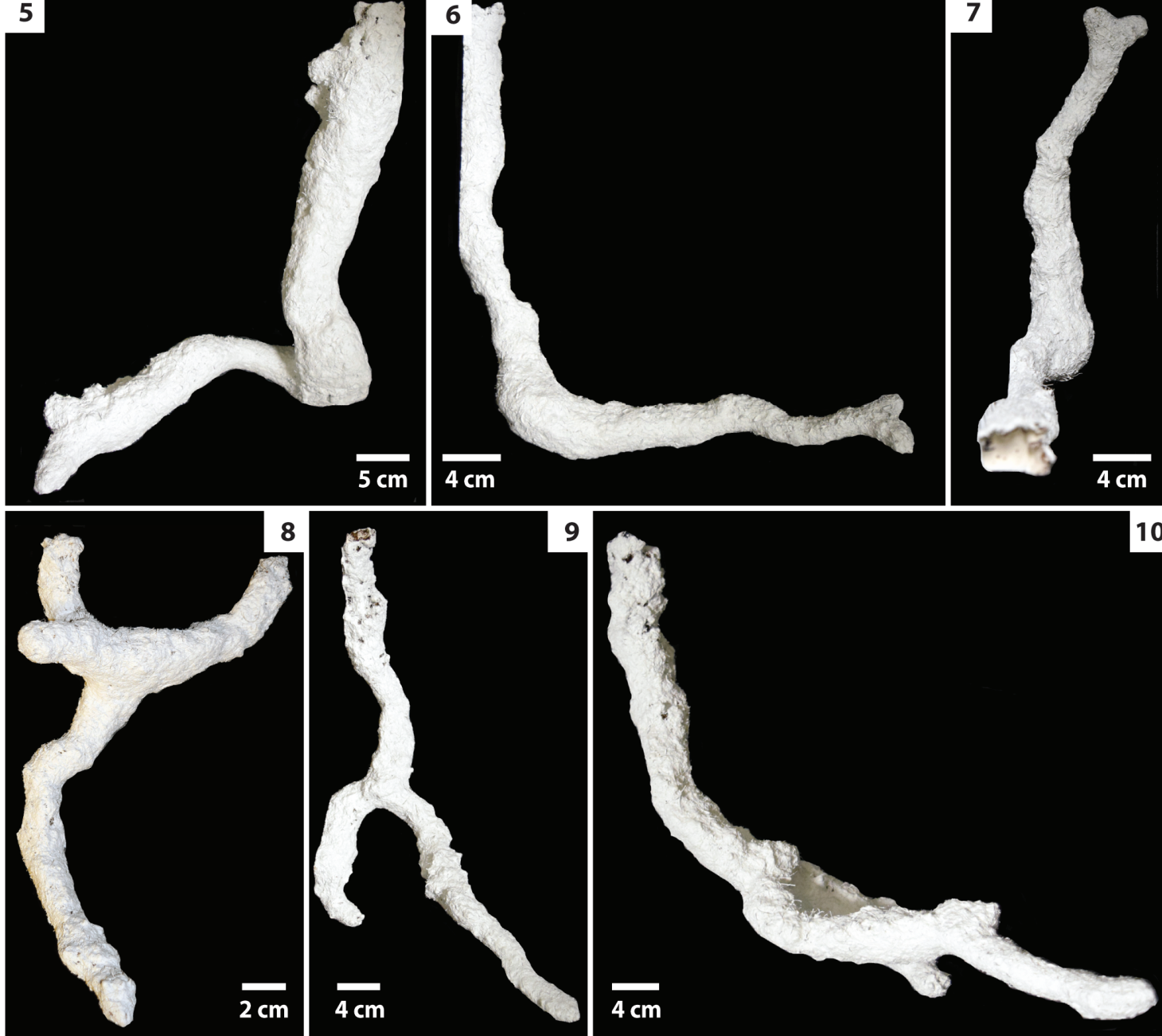

8
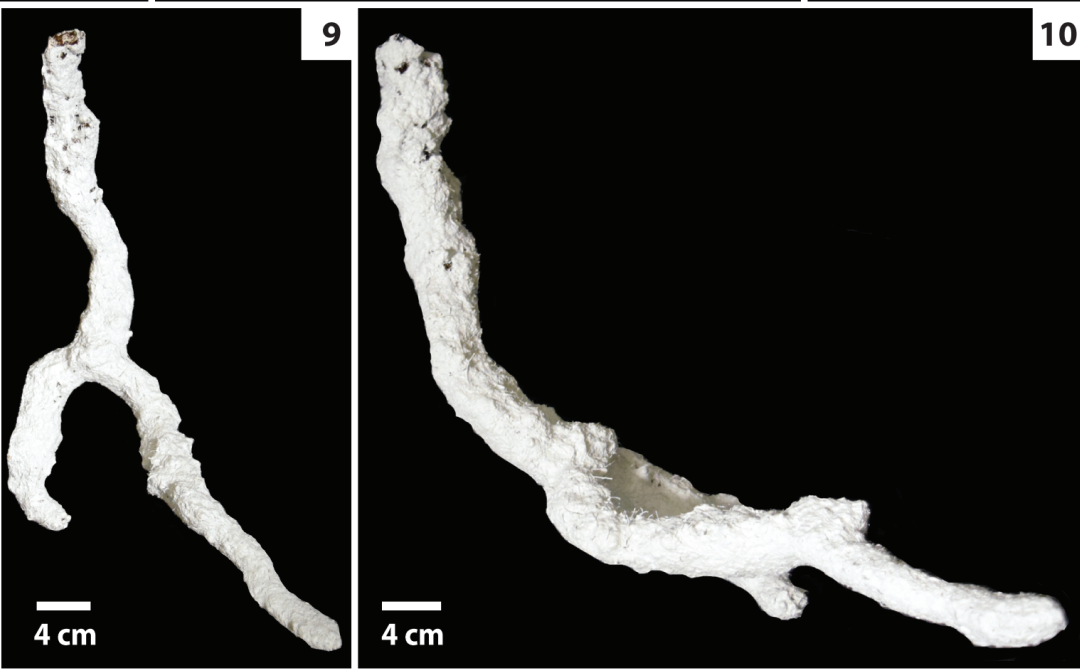

FIGURE 9. Pelinobius muticus burrow casts. 1-3, Side views of vertical, sinuous burrows with a laterally expanded terminal chamber (PM6, PM1, PM3, respectively). 4-5, Oblique and side views of a large diameter, vertical sinuous burrow ending with a horizontal tunnel (PM5). 6-7, Side and top views of a vertical burrow terminating in a horizontal tunnel (PM4). The burrow ends with two bifurcating tunnels. 8, Vertical, branching burrow (PM2). 9-10, Oblique and side view of a vertical, sinuous burrow with two branching tunnels (PM7). 


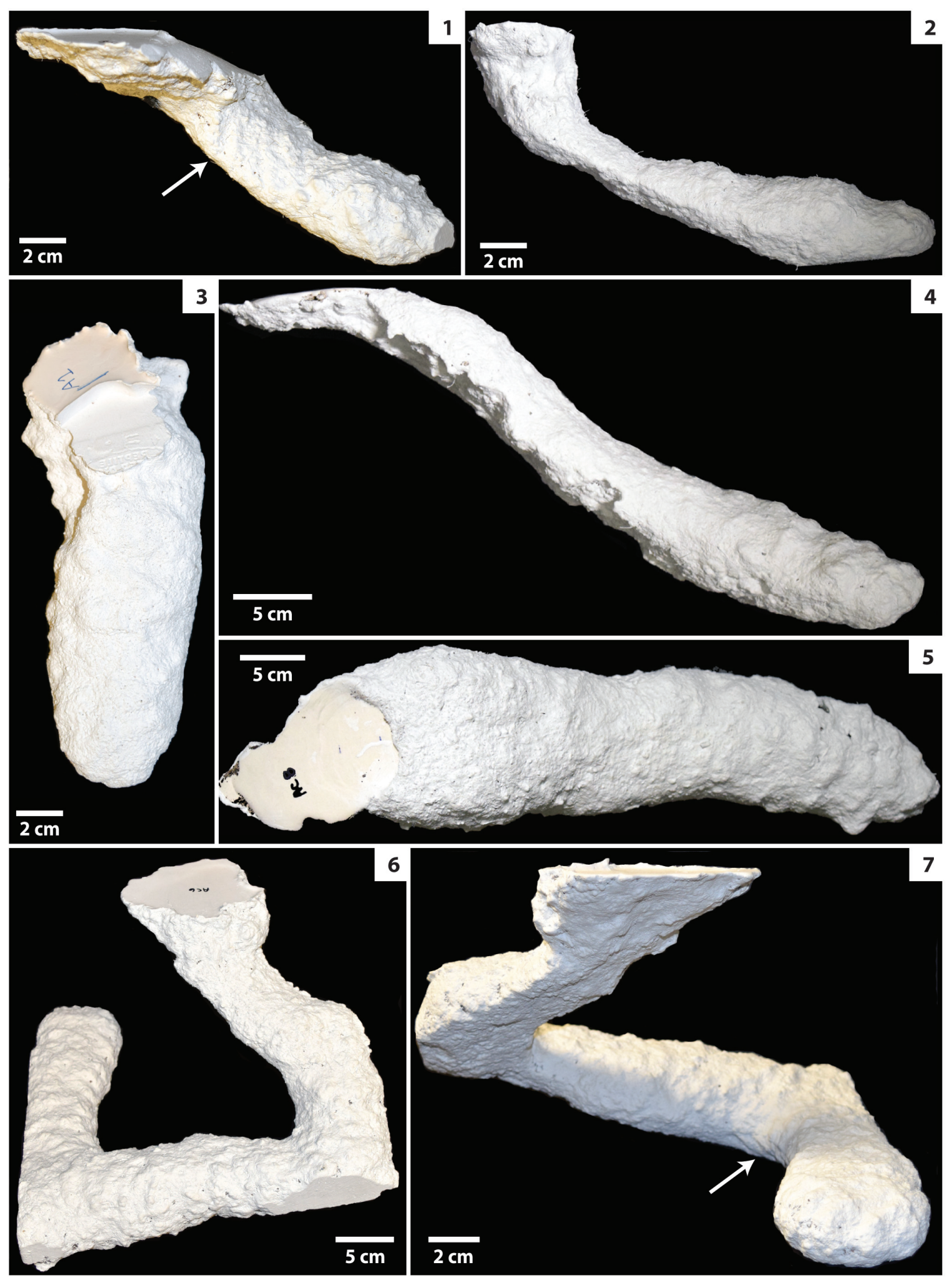

FIGURE 10. Aphonopelma chalcodes burrow casts. 1, Side view of a subvertical tunnel with a series of parallel ridges along the tunnel wall (at arrow) (AC3). 2, Side view of a subvertical tunnel with a vertical entrance shaft and a laterally expanded terminal chamber (AC7). 3, Top view of a subvertical tunnel (AC1). 4-5, Side and top views of a subvertical tunnel with a changing slope along its length (AC8). 6-7, Oblique and side views of a helical burrow with a series of parallel ridges along the tunnel wall (at arrow) and a laterally expanded terminal chamber (AC6). 


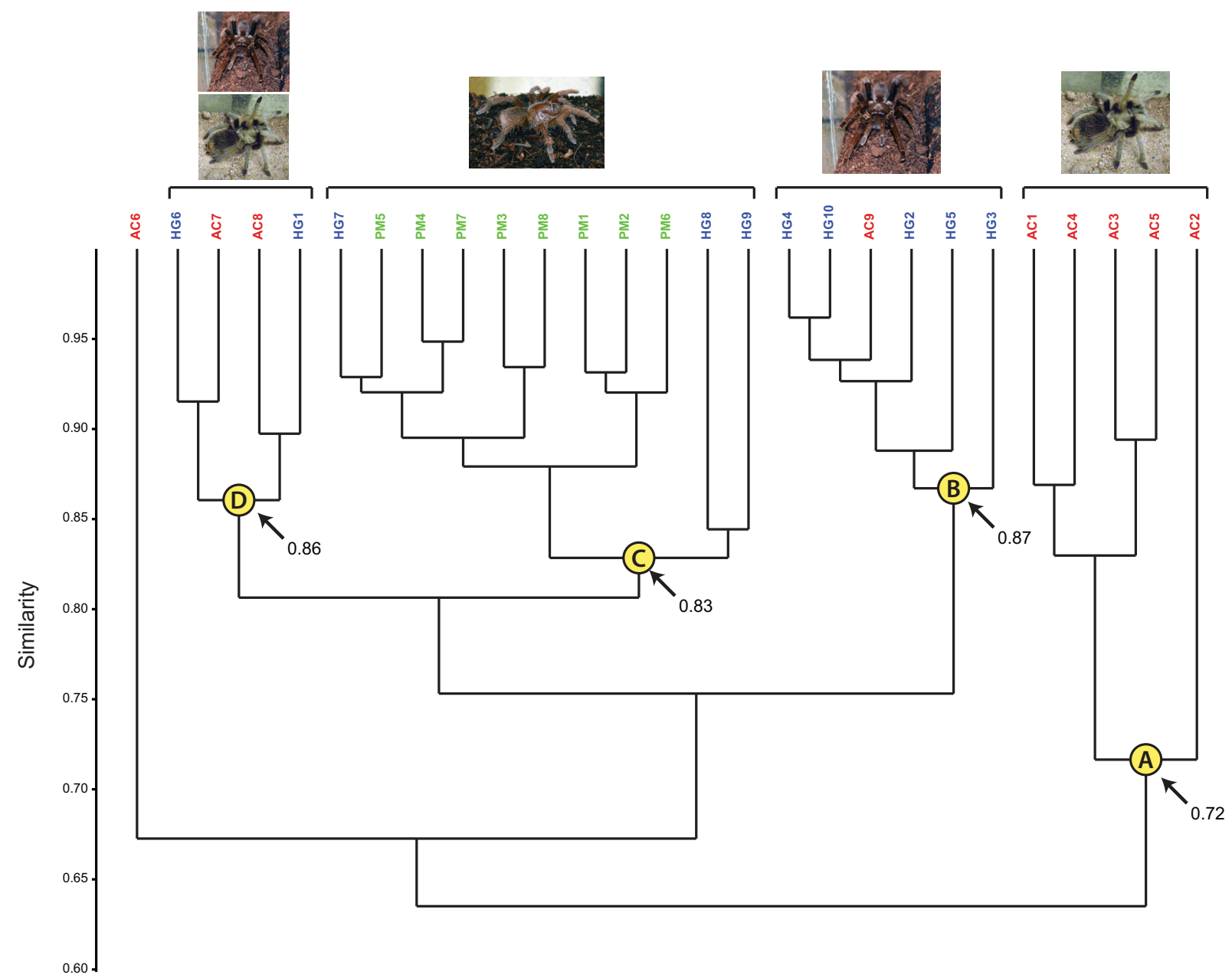

FIGURE 11. Cluster analysis of burrows produced by Hysterocrates gigas (HG, blue, $\mathrm{n}=10$ ), Pelinobius muticus (PM, green, $n=8$ ), and Aphonopelma chalcodes ( $A C$, red, $n=9$ ). Burrows sort into four moderately to highly similar $(B C>$ 0.7 ) clusters by trace maker and architecture (A-D). Cluster $A$ consists entirely of burrows of $A$. chalcodes; Cluster $B$ consists of five burrows of $H$. gigas $(83 \%)$ and a single burrow of $A$. chalcodes $(17 \%)$; Cluster $C$ consists of eight burrows of $P$. muticus $(73 \%)$ and three burrows of $H$. gigas $(27 \%)$; Cluster D consists of two burrows each of $H$. gigas $(50 \%)$ and P. muticus (50\%). Values located at the labeled nodes of the dendrogram are the mean Bray-Curtis similarity score of all burrows emanating from that node cluster.

ately similar cluster $(2)(B C>0.68)$ along with the burrows of trapdoor spiders and half of the salamander burrows. These burrows were linked primarily by their subvertical to vertical orientation (mean slope $>40^{\circ}$ ). The second moderately similar cluster (1) $(B C>0.67)$ was composed of half of the burrows of Aphonopelma chalcodes as well as burrows of the scorpion, salamander, and skink. These burrows were linked primarily by their subhorizontal orientation (mean slope $<40^{\circ}$ ).

\section{DISCUSSION}

\section{Burrow Morphology and Trace Maker}

Each of the three species of tarantulas produced a distinct burrow architecture with some variation in burrow properties, including length, depth, and complexity, largely related to time of occupation. There were no recognizable differences between burrows produced by male and female specimens of each species; however, the sample size of burrows within each species may not be large enough to detect these differences.

The qualitatively and quantitatively recognizable differences in the burrows between the three tarantula species are particularly striking given the similarity in body plans of the trace makers. The only properties that were consistently similar between the three species of tarantulas were the number of surface openings (1) and the width-toheight ratio $(\sim 1.1)$ (Appendix 3$)$. The width-toheight ratio varies from nearly circular to elliptical, 


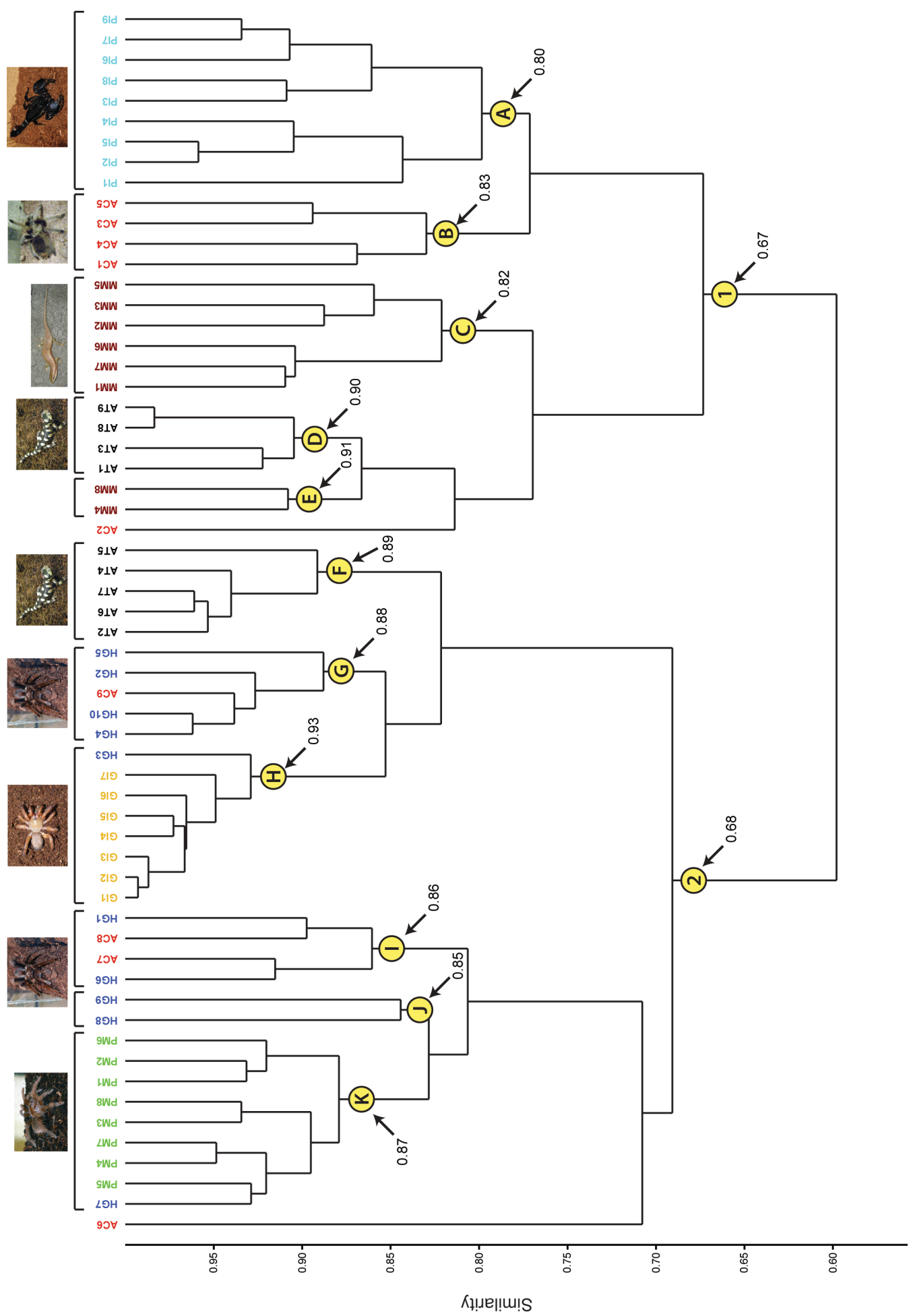

FIGURE 12. All animal burrow cluster diagram. Cluster analysis of the burrows produced by Hysterocrates gigas (HG, blue, $n=10$ ), Pelinobius muticus (PM, green, $n=8$ ), and Aphonopelma chalcodes (AC, red, $n=9$ ), the scorpion Pandinus imperator ( $\mathrm{Pl}$, light blue, $\mathrm{n}=9$ ), trapdoor spider Gorgyrella inermis ( $\mathrm{Gl}$, yellow, $\mathrm{n}=7$ ) (yellow), the salamander Ambystoma tigrinum (AT, black, $n=9$ ) (red), and the skink Mabuya multifasciata (MM, purple, $n=8)($ green). The burrows sort into 11 highly similar $(B C>0.80)$ clusters $(A-K)$, each populated primarily by the burrows of a single trace maker: $A=100 \%$ P. imperator $(n=9) ; B=100 \%$ A. chalcodes $(n=4) ; C=100 \%$ M. multifasciata $(n=6) ; D=100 \% A$. tigrinum $(n=4) ; E=100 \%$ M. multifasciata $(n=2) ; F=100 \%$ A. tigrinum $(n=5) ; G=80 \%$ H. gigas $(n=4) ; H=88 \%$ G. inermis $(n=7) ; I=50 \% H$. gigas $/ A$. chalcodes $(n=2$ each); $J=100 \% H$. gigas $(n=2) ; K=89 \% P$. muticus $(n=8)$. 
but does not exceed 1.8, and is reflective of the general tarantula body form with a broad, rounded body held close to the ground. The laterally expanded chambers, especially along more horizontal elements of the burrows, best reflect this body form of the tarantulas. The presence of elongate series of ridges produced by the pedipalps during excavation is an additional, more qualitative, link of these different burrow architectures to their tarantula trace makers. While other continental trace makers such as decapods and mammals can produce similar bioglyphs on burrow walls (e.g., Hasiotis et al., 1993; Gobetz, 2006; Hembree and Hasiotis, 2008; Melchor et al., 2010), those produced by tarantulas are wider than those previously described and occur in parallel series of paired sets.

In general, the burrows of Hysterocrates gigas and Pelinobius muticus were found to be the most similar using the Bray Curtis analysis (Figure 11), even though fewer of the burrow properties of $H$. gigas and Aphonopelma chalcodes were significantly different (Appendix 3). The division was based on the vertical orientation of large portions of the burrows of $H$. gigas and $P$. muticus and the generally subhorizontal orientation of $A$. chalcodes burrows. The vertical orientation of $H$. gigas and $P$. muticus burrows is related to their chimney climbing technique (i.e., Shäfer and Craig, 1972); these burrows do not possess obvious floors since the tarantulas move in any orientation and direction through the shafts. Aphonopelma chalcodes, on the other hand, consistently walked on a single surface through the entire burrow; these subhorizontal tunnels had a well-defined floor and tended to be more elliptical in cross section ( 1.2).

Tarantula burrows from previous field studies (Kotzman, 1990; Pérez-Miles et al., 2005; Machkour M'Rabet et al., 2007) can be qualitatively compared to the burrows produced in this study. Quantitative comparisons cannot be made due to the limited number of measurements provided in these studies. The simple burrows of Selenocosmia stirlingi, Eupalaestrus weijenberghi, and Acanthoscurria suina were most similar to those of Hysterocrates gigas; however, most chambers of $H$. gigas were vertically oriented rather than horizontal. Burrows of Brachypelma vagans had a variable morphology from simple to complex, related to the age of the tarantula. Burrows of $B$. vagans are generally unique from the burrows of tarantulas in this study due to combination of simple shafts and a high number of chambers.
Comparison of the tarantula burrows to those of other animals indicates that the quantitative properties of the burrows can be used to sort them largely according to trace maker, especially at higher levels of similarity $(B C>0.85)$. This differentiation even occurred when individual trace makers produced more than one burrow architecture. While many of the burrows had some similar properties, the aggregate differences allow them to be distinguished even when the trace makers had similar body morphologies.

The trapdoor spider Gorgyrella inermis constructs vertical to subvertical, cylindrical shafts with circular cross sections and rounded terminal chambers (Figure 5) (Hils and Hembree, 2015). These were constructed to accommodate vertical chimney climbing as well as the spider's general body form with eight legs radiating out from the prosoma to form a generally circular shape. As a result, $G$. inermis burrows are most similar to those of Hysterocrates gigas and Pelinobius muticus, but still largely distinct due to their short length, circular cross section, and low tortuosity (Appendix 4) even though they are all produced by spiders.

The scorpion Pandinus imperator constructs subhorizontal to helical tunnels with laterally expanded chambers (Figure 5) (Hembree, 2014). Scorpions have large pedipalps modified into pincers, an elongate, low body, and a long tail and walk with their bodies held low to the ground. As a result, their burrows have elliptical cross sections with arched roofs and flat, well-defined floors. The burrows of $P$. imperator are most similar to those of Aphonopelma chalcodes (Figure 12) due to similarities in slope and $\mathrm{W} / \mathrm{H}$ ratio, but do form a discrete cluster due to their greater widths, lower heights, and greater circumferences of tunnels (Appendix 4).

The salamander Ambystoma tigrinum constructs subhorizontal to subvertical burrows with an elliptical cross section that may be J- to Y-shaped (Figure 5) (Dzenowski and Hembree, 2014). The shafts and tunnels are straight to curved, with flat floors and curved walls and roofs. The variation in orientation of these burrows leads to their differentiation using the Bray-Curtis analysis (Figure 12); horizontal burrows are more similar to those of Aphonopelma chalcodes, whereas subvertical burrows are more similar to those of Hysterocrates gigas and Pelinobius muticus. Despite this split, the salamander burrows form discrete clusters based on their low width, height, and circumference and high tortuosity (Appendix 4). 
The skink Mabuya multifasciata constructs subhorizontal, branching and U-shaped burrows with elliptical cross sections, concave roofs and floors, and curved walls (Figure 5) (Catena and Hembree, 2014). Skinks have elongate, but narrow bodies with reduced limbs that are held close to the body and move through the substrate through lateral undulation. This movement results in a flattened, cylindrical burrow with frequent curves along its length. The orientation of these burrows makes them most similar to burrows of Aphonopelma chalcodes, yet they are distinct in their lower relative dimensions (width, height, and circumference) as well as depth, length, and tortuosity (Appendix 4).

\section{Burrow Morphology and Behavior}

Fundamentally, burrows and other biogenic structures are a product of animal behavior in response the environment (Bromley, 1996). The different burrow architectures of the three species of tarantulas were all constructed for dwelling. The similarities in the morphology of the burrows were partially a result of this use toward a single, basic behavior. The dwelling burrows are used for shelter from surface conditions including light, excessive temperatures (high and low) and low humidity as well as predator avoidance. Differences in the individual elements of the burrows were related to variations in the use of the burrows as dwellings. Chambers, for example, were either large and welldeveloped in the case of Hysterocrates gigas burrows or smaller and less distinct as in burrows of Pelinobius muticus and Aphonopelma chalcodes. These differences relate to the amount of time spent in the chamber. Specimens of $H$. gigas spent most of their time in their burrow chambers, whereas $P$. muticus and $A$. chalcodes were often in the shafts below the burrow opening or were frequently leaving the burrow to actively hunt, respectively.

In addition to their use as dwelling, the tarantula burrows also had secondary uses that affected their morphology. The burrows of Hysterocrates gigas and Pelinobius muticus were often used as sites for ambush predation. This behavior was associated with burrows possessing shafts connected to the surface and a partially to fully concealed opening. These features provided the tarantula with a concealed location to capture prey at the surface and quickly bring them into the subsurface for consumption with minimal time of exposure. This action did not produce any recognizable (or preservable) features with the exception of some minor disruption of loose sediment around the burrow opening. Burrows of $H$. gigas also seemed to be designed for predator avoidance. Several burrows maintained over long periods of time ( $>90$ days) possessed a deep, vertical shaft below the main dwelling chamber. These shafts were used by the tarantula when the burrow opening was disturbed; the length and depth of the shaft made it difficult to locate and extract these tarantulas from their burrows. A study of interactions between the tarantula Eupalaestrus weijenberghi and pompilid wasps demonstrated that these tarantulas also used narrow tunnels extending from their chambers to escape the wasps (Costa et al. 2004). Blind, sinuous branches in the burrows of $P$. muticus may be similarly related to predator avoidance. The burrow openings of $P$. muticus were frequently sealed with sediment which would hinder the entrance of predators into the tunnels. If the intruding animal could remove the seal, as is the case with some wasps (Costa et al., 2004), the branching tunnels may be used to provide multiple escape paths for the tarantula.

The method of burrow construction, primarily direct excavation, was reflected in the irregular dimensions of the burrow elements (shafts, tunnels, chambers) along their length as well as the irregularity of the walls. Irregularities in burrow elements and walls are the result of continuous starting and stopping of excavation as the tarantulas removed sediment from the developing tunnels and shafts, carried it to the surface for deposition, and then returned to continue burrowing. This pattern of excavation appears to have hindered uniformity in the construction. In addition, multiple series of scratch marks were produced by the scraping of the chelicerae and pedipalps on the burrow walls to removed sediment.

Burrows of Gorgyrella sp., Pandinus imperator, Ambystoma tigrinum, and Mabuya multifasciata were also used for dwelling and feeding purposes, yet these behavioral similarities do not result in identical architectures. Many of the differences in burrow morphology are a result of differences in burrowing techniques (as well as tracemaker morphology). The burrows of Gorgyrella sp. were excavated using the pedipalps; sediment was removed in a circular fashion from around the spider's body, wrapped in silk, and thrown from the open burrow (Hils and Hembree, 2015). This process resulted in a smooth-walled, uniform vertical tube as the spider descended into the sediment. Pandinus imperator, whose burrows were most similar to those of Aphonopelma chalcodes, bur- 
rows by excavation in a manner similar to the tarantulas, using its first two pairs of walking legs to excavate, lift, and carry sediment out of the burrow (Hembree, 2014). Ambystoma tigrinum uses a combination of excavation and intrusion techniques to burrow. The burrow is started by excavating a shallow tunnel with its forelimbs followed by expansion of the burrow by compressing sediment with the head and limbs (Dzenowski and Hembree, 2014). Mabuya multifasciata uses an intrusion burrowing technique as well, forcing itself into loose sediment with lateral undulation as well as head and limb movement (Catena and Hembree, 2014). As a result of these burrowing techniques, burrows of $A$. tigrinum and $M$. multifasciata were typically simple, subvertical tunnels that closely matched the form and dimensions of the trace maker's body.

\section{Identification of Tarantula Burrows in the Fossil Record}

The successful identification of the trace maker of a fossil burrow requires the understanding of the burrow architectures produced by extant animals. The limited number of detailed descriptions of modern tarantula burrows, especially three-dimensional casts, hinders the recognition of their ancient equivalents in the fossil record. Studies of modern burrowing animals, such as the one described in this paper, provide a set of defining burrow characteristics (or ichnotaxobases) that can be used to help diagnose the trace maker and trace-making behaviors of a fossil burrow. Useful ichnotaxobases consist of architecture, overall shape, orientation with respect to the sediment surface, internal structure, and surficial features (Bromley, 1996; Bertling et al., 2006).

Architecture. Tarantula burrows include straight, vertical shafts, sinuous vertical shafts with or without branches, and subvertical, straight to helical tunnels. All burrow architectures include vertical and laterally expanded chambers, which may be located at the beginning or end of shafts and tunnels or at branch points. All burrow architectures possess one surface opening.

Overall shape. Burrow openings, shafts, and tunnels are circular to elliptical in cross section, whereas chambers are typically circular in cross section. Shafts and tunnels are straight to sinuous and are irregular along their length; chambers are up to twice as large as adjoining shafts and tunnels.

Orientation. Burrow elements vary in slope from horizontal $\left(0^{\circ}\right)$, oblique $\left(25-70^{\circ}\right)$, and vertical $\left(90^{\circ}\right)$ relative to the sediment surface.
Internal structure. Tarantula burrows possess no distinguishable sediment lining, however, thin layers of silk are typically added to the burrow walls, especially near the sediment surface. The upper portion of the burrow may be partially backfilled with sediment sealing the burrow opening; the rest of the burrow is kept open and may be filled passively.

Surficial features. The sides of shaft and tunnel wall may possess multiple series of elongate, paired parallel ridges (1-3 $\mathrm{mm}$ wide and $1-4 \mathrm{~mm}$ high).

\section{Paleoecological and Paleoenvironmental Significance}

With a known body fossil record extending to the Carboniferous and the fossorial nature of many different groups of spiders, spider burrows should be preserved in continental strata. There have been only a few instances, however, where terrestrial fossil burrows, including Skolithos and Macanopsis, have been attributed to the activity of spiders (Ratcliffe and Fagerstrom, 1980; Bown and Kraus, 1983; Hasiotis, 2002; Retallack et al., 2003; Catena et al., 2016). Given the size, depth, complexity, and continued maintenance of the open burrows produced by the tarantulas in this and other studies, it is clear that these structures should be expected in the trace fossil record.

The proper interpretation of the associated behaviors and trace makers of fossil burrows is important because they provide an improved understanding of paleoecosystems. Trace fossils provide a record of organisms with low preservation potential, in particular soft-bodied organisms living in terrestrial environments such as annelids and arthropods. This record is crucial for reconstructing soil ecosystems through time as soft-bodied organisms may comprise a large part of the biomass (Lavelle and Spain, 2005). Consequently, the diversity of trace fossils can be used to improve estimates of biological abundance and diversity (Frey, 1975). Spiders are exclusively carnivores and are important predators of invertebrates and small vertebrates (Clarke and Grant, 1968; Reichert and Lockley, 1984; Hodge, 1999). Spiders are also prey for other animals including lizards, rodents, and birds. As a result, high density and diversity of spiders can be indicative of a healthy ecosystem. Recognition of spider burrows can, therefore, improve the reconstructions of ancient soil food webs even in the absence of body fossils.

The identification of the burrows of spiders would also provide an improved evolutionary and 
paleogeographic history of the group. Body fossils of spiders are rare in the Paleozoic and younger fossils are primarily preserved in amber (Shear, 1994). Burrows are more likely to be preserved than the spiders themselves due to their construction in the soil subsurface and the fact that they do not degrade over time. In fact, diagenetic alteration often improves the visibility of trace fossils (Savrda, 2007). Fossil burrows would also be preserved in the environments actually occupied by spiders since trace fossils are generally not transported from where they were produced (Bromley, 1996). The record of fossil burrows would be especially helpful with improving our understanding of the evolutionary history of tarantulas (and mygalomorphs in general) since their fossil record only extends to the Neogene despite the fact that mygalomorphs represent basal group of the Opisthothelae.

Burrowing terrestrial animals are important contributors to soil formation (Lavelle and Spain, 2005). Recognition of the effects of different types of burrowing animals such as large spiders on soils can, therefore, inform on the causes for the degree of pedogenic development in specific environments. In the laboratory experiments, tarantulas transported sediment from the subsurface to the surface through burrow construction. Hysterocrates in particular moved significant quantities of sediment from depths of up to $50 \mathrm{~cm}$. This transport, mixing, and mounding of sediment has the effect of increasing rates of mineral weathering and clay production by continuously moving mineral grains to the surface (Bromley, 1996). Deposition of excavated sediment increases the burial of surface organic matter increasing the organic content of the soil and making it available for infaunal deposit feeders (Lavelle and Spain, 2005).

Open burrows also provide conduits for the infiltration of water and oxygen into the soil, increasing rates of chemical weathering in the soil, promoting leaching of soluble cations, and the translocating clays deeper into the soil profile (e.g., Hasiotis, 2007). The large burrows produced by Hysterocrates and Aphonopelma were typically left open, allowing water sprayed at the surface to flow into the sediment. When visible through the sides of the terrarium, the sediment along the length of the burrow was wetter than that of the surrounding sediment. Large, open burrows, therefore, increase the effective surface area of the soil. Finally, soil animals such as tarantulas can introduce organic matter into the soil through feeding and the burial of molts. In the laboratory, all three species of tarantulas fed inside their burrows and deposited the remains of their prey in the tunnels and chambers. Over time, this organic matter was buried as the burrows were modified, becoming part of the soil matrix. The same often occurred when the tarantulas molted. Molting occurred in the burrow chambers; when the molt was complete some individual removed it from the burrow but other left the molt in the burrow where it was eventually buried. These were the tarantulas' most visible contributions to the organic content of the sediment. There was little evidence of burial of fecal material, although it is expected that this occurred.

\section{CONCLUSIONS}

Three species of burrowing tarantulas were studied to determine their burrowing techniques, resulting burrow morphologies, and the behaviors associated with the burrows. Each species engaged in relatively similar methods of burrow construction, using their pedipalps and chelicerae to excavate and carry sediment. This excavated material was deposited away from the burrow opening, used to build up a turret around the opening, or mixed with silk and used to cover the opening. Each species of tarantula produced a unique burrow architecture: 1) Hysterocrates gigas produced elongate, cylindrical shafts with large, ovoid chambers near the sediment surface and at depth, 2) Pelinobius muticus produced subvertical sinuous shafts with and without branches, and 3) Aphonopelma chalcodes produced straight to curved, subhorizontal tunnels. All of the tarantulas used their burrows as permanent dwellings with secondary uses for ambush predation and predator avoidance.

These types of neoichnological studies have a vital role in the interpretation of continental paleoecosystems and paleoenvironments. The burrows produced by tarantulas have morphologies similar to Skolithos, Macanopsis, Psilonichnus, and Camborygma. The results of these experiments can be useful in interpreting the behavioral significance of these and similar ichnogenera in continental deposits. The array of morphologies produced by tarantulas were all fundamentally associated with dwelling behavior, but were also used for ambush predation. While dwelling can often be interpreted, especially when a chamber is present, ambush predation is much more difficult to discern. These types of experiments are also critical to the interpretation of the trace makers of these ichnogenera in continental settings. There are numerous conti- 
nental burrowers, producing an array of distinct and similar types of burrows. Arthropods in particular are abundant and diverse components of soil ecosystems, and likely have been since the middle Paleozoic. Knowledge of the burrows of modern soil arthropods is necessary for accurate interpretations of the paleoecology of terrestrial settings; especially when body fossils are lacking. Qualitatively each tarantula species produced a unique burrow morphology that was distinct from those of the others as well as from a species of trapdoor spider, scorpion, salamander, and skink. In addition, quantitative comparison of tarantula burrows with those of other soil animals showed that their burrows could be distinguished based on a set of measureable properties. This provides evidence that the trace makers of well-preserved fossil burrows could also be determined using similar methods.

\section{ACKNOWLEDGMENTS}

I would thank two anonymous reviewers for their comments and suggestions that improved this manuscript. This work would not have been possible without generous funding from the National Science Foundation (EAR-0844256) and the American Chemical Society Petroleum Research Fund (49387-UNI8). I also thank J. Michael Hils and $\mathrm{E}$. Swaninger for their assistance in the Continental Ichnology Research Laboratory (CIRL) at Ohio University.

\section{REFERENCES}

Bertling, M., Braddy, S.J., Bromley, R.G., Demathiey, G.R., Genise, J., Mikulas, R., Nielsen, J.K., Rindsberg, A.K., Schlirf, M., and Uchman, A. 2006. Names for trace fossils: a uniform approach. Lethaia, 39:265-286.

Bowen, J. and Hembree, D. 2014. Neoichnology of two spirobolid millipedes: improving the understanding of the burrows of soil detritivores. Palaeontologia Electronica, 17.1.18A:1-48 palaeo-electronica.org/content/2014/709-neoichnology-of-spirobolids

Bown, T.M. and Kraus, M.J. 1983. Ichnofossils of the alluvial Willwood Formation (Lower Eocene), Bighorn Basin, Northwest Wyoming, USA. Palaeogeography, Palaeoclimatology, Palaeoecology, 43:95-128.

Bray, R.J. and Curtis, J.T. 1957. An ordination of the upland forest communities of southern Wisconsin. Ecological Monographs, 27(4):325-349.

Bromley, R.G. 1996. Trace Fossils: Biology, Taphonomy and Applications. Chapman and Hall, London, United Kingdom.

Catena, A.M. and Hembree, D.I. 2014. Biogenic structures of burrowing skinks: neoichnology of Mabuya multifasciata (Squamata: Scincidae), p. 343-369. In Hembree, D.I., Platt, B.F., and Smith, J.J. (eds.), Experimental Approaches to Understanding Fossil Organisms: Lessons from the Living. Topics in Geobiology 41. Springer Publishing, Dordrecht.

Catena, A.M., Hembree, D.I., Saylor, B.Z., Anaya, F., and Croft, D.A. 2016. Paleoenvironmental analysis of the Neotropical fossil mammal site of Cerdas, Bolivia (middle Miocene) based on ichnofossils and paleopedology. Palaeogeography, Palaeoclimatology, Palaeoecology, 459:423-439.

Clarke, R.D. and Grant, P.R. 1968. An experimental study of the role of spiders as predators in a forest litter community. Part 1. Ecology, 49(6):1152-1154.

Costa, F.G., Pérez-Miles, F., and Mignone, A. 2004. Pompilid wasp interactions with burrowing tarantulas: Pepsis cupripennis versus Eupalaestrus weijenberghi and Acanthoscurria suina (Araneae, Theraphosidae). Studies on Neotropical Fauna and Environment, 39:37-43.

Dunlop, J.A. 2010. Geologic history and phylogeny of Chelicerata. Arthropod Structure \& Development, 39:124-142

Dunlop, J.A., Harms, D., and Penney, D. 2008. A fossil tarantula (Araneae: Theraphosidae) from Miocene Chiapas amber, Mexico. Revista Ibérica de Aracnología, 15:9-17

Dunlop, J.A., Penney, D., and Jekel, D. 2013. A summary list of fossil spiders and their relatives. In Platnick, N.l. (ed.), The world spider catalog, version 14.0 American Museum of Natural History, http:// research.amnh.org/entomology/spiders/catalog/ index.html

Dzenowski, N.D. and Hembree, D.I., 2014. The neoichnology of two terrestrial salamanders: quantifying amphibian burrows using modern analogs, p. 305341. In Hembree, D.I., Platt, B.F., and Smith, J.J. (eds.), Experimental Approaches to Understanding Fossil Organisms: Lessons from the Living. Topics in Geobiology 41. Springer Publishing, Dordrecht.

Ferretti, N.E. and Ferrero, A.A. 2008. Courtship and mating behavior of Grammostola schulzei (Schmidt 1994) (Araneae, Theraphosidae), a burrowing tarantula from Argentina. Journal of Arachnology, 36:480483.

Frey, R.W. 1975. The realm of ichnology, its strengths and limitations, p. 13-38. In Frey, R.W. (ed.), The Study of Trace Fossils. Springer-Verlag, New York.

Genise, J.F. 2017. Ichnoentomology: Insect Traces in Soils and Paleosols. Topics in Geobiology 37. Springer Publishing, Dordrecht.

Gertsch, W.J. 1949. American Spiders. D. Van Nostrand Company, INC., Toronto.

Gobetz, K.E. 2006. Possible burrows of mylagaulids (Rodentia: Aplodontoidea: Mylagaulidae) from the late Miocene (Barstovian) Pawnee Creek Formation of northeastern Colorado. Palaeogeography, Palaeoclimatology, Palaeoecology, 237:119-136. 
Hamilton, D.E., Mclntyre, N.E., and Densmore, L.D. 2012. Using implanted passive integrated transponders to monitor long-term burrow fidelity in a theraphosid spider, Aphonopelma hollyi. The Southwestern Naturalist, 54:144-147.

Hammer, Ø., Harper, D.A.T., and Ryan, P.D. 2001. PAST: Paleontological Statistics software packages for education and data analysis. Palaeontologia Electronica, $4(1): 1-9$ palaeo-electronica.org/2001_1/past/issue1_01.html

Hasiotis, S.T. 2002. Continental Trace Fossils. SEPM Short Course Notes, 51. Society for Sedimentary Geology, Tulsa, Oklahoma.

Hasiotis, S.T. 2007. Continental ichnology: fundamental processes and controls on trace fossil distribution. The Continental Realm, p. 268-284. In Miller, W. (ed.), Trace Fossils: Concepts, Problems, Prospects. Elsevier Science.

Hasiotis, S.T., Mitchell, C.E., and Dubiel, R.F. 1993. Application of morphologic burrow interpretation to discern continental burrow architects: lungfish or crayfish? Ichnos, 2:315-333.

Hembree, D.I. 2013. Neoichnology of the whip scorpion Mastigoproctus giganteus: complex burrows of predatory terrestrial arthropods. PALAIOS, 28:141-162.

Hembree, D.I. 2014. Large, complex burrows of terrestrial invertebrates: neoichnology of Pandinus imperator, p. 229-263. In Hembree, D.I., Platt, B.F., and Smith, J.J. (eds.), Experimental Approaches to Understanding Fossil Organisms: Lessons from the Living. Topics in Geobiology 41. Springer Publishing, Dordrecht.

Hembree, D.I. 2016. Using experimental neoichnology and quantitative analyses to improve the interpretation of continental trace fossils. Ichnos, 23:262-297.

Hembree, D.I. and Hasiotis, S.T. 2006. The identification and interpretation of reptile ichnofossils in paleosols through modern studies. Journal of Sedimentary Research, 76:575-588.

Hembree, D.I. and Hasiotis, S.T. 2008. Miocene vertebrate and invertebrate burrows defining compound paleosols in the Pawnee Creek Formation, Colorado, USA. Palaeogeography, Palaeoclimatology, Palaeoecology, 270:349-365.

Hembree, D.I., Johnson, L.M., and Tenwalde, R.W. 2012. Neoichnology of the desert scorpion Hadrurus arizonensis: burrows to biogenic cross lamination. Palaeontologia Electronica, 15.1.10A:1-14 palaeo-electronica.org/content/2012-issue-1-articles/ 192-neoichnology-of-scorpions

Hils, J.M. and Hembree, D.I. 2015. Neoichnology of the burrowing spiders Gorgyrella inermis (Mygalomorphae: Idiopidae) and Hogna lenta (Araneomorphae: Lycosidae). Palaeontologica Electronica, 18.1.7A:162 palaeo-electronica.org/content/2015/1057-neoichnology-of-spiders

Hodge, M.A. 1999. The implications of intraguild predation for the role of spiders in biological control. Journal of Arachnology, 27(1):351-362.
Knaust, D. 2012. Trace-fossil systematics, p. 79-102. In Knaust D. and Bromley, R.G. (eds.), Trace Fossils as Indicators of Sedimentary Environments. Elsevier, Amsterdam.

Kotzman, M. 1990. Annual activity patterns of the Australian tarantula Selenocosmia stirlingi (Araneae, Theraphosidae) in an arid area. Journal of Arachnology, 18(2):123-130.

Lavelle, P. and Spain, A.V. 2005. Soil Ecology. Springer Publishing, Dordrecht.

Machkour M'Rabet, S., Hénaut, Y., Sepúlveda, A., Rojo, R., Calmé, S., and Geissen, V. 2007. Soil preference and burrow structure of an endangered tarantula, Brachypelma vagans (Mygalomorphae: Theraphosidea). Journal of Natural History, 41(17-20):10251033.

Marshall, S.D. 1996. Tarantulas and Other Arachnids. Barron's Educational Series Inc., Hauppauge, New York.

Meadows, P.S. 1991. The environmental impact of burrows and burrowing animals - conclusions and a model, p. 327-388. In Meadows, P.S. and Meadows, A. (eds.), The Environmental Impact of Burrowing Animals and Animal Burrows. Clarendon Press, Oxford.

Melchor, R.N., Genise, J.F., Farina, J.L., Sánchez, M.V., Sarzetti, L., and Visconti, G. 2010. Large striated burrows from fluvial deposits of Neogene Vinchina Formation, La Rioja, Argentina: a crab origin suggested by neoichnology and sedimentology. Palaeogeography, Palaeoclimatology, Palaeoecology, 291:400418.

Pechenik, J.A. 1991. Biology of the Invertebrates (second edition). Wm. C. Brown Publishers, Dubuque.

Pérez-Miles, F., Costa, F.G., Toscano-Gadea, C., and Mignone, A. 2005. Ecology and behavior of the 'road tarantulas' Eupalaestrus weijenberghi and Acanthoscurria suina (Araneae, Theraphosidae) from Uruguay. Journal of Natural History, 39(6):483-498.

Pickford, M. 2000. Fossil spider's webs from the Namib Desert and the antiquity of Seothyra (Araneae, Eresidae). Annales de Paleontology, 86(3):147-155.

Ratcliffe, B.C. and Fagerstrom, J.A. 1980. Invertebrate Lebensspuren of Holocene floodplains: their morphology, origin, and paleoecological significance. Journal of Paleontology, 54(3):614-630.

Reichert, S.E. and Lockley, T. 1984. Spiders as biological control agents. Annual Review of Entomology, 29(1):299-320.

Retallack, G.J., Smith, M.H., and Ward, P.D. 2003. Vertebrate extinction across Permian-Triassic boundary in Karoo Basin, South Africa. Geological Society of America Bulletin, 115(9):1133-1152.

Rupert, E.E., Fox, R.S., and Barnes, R.D. 2004. Invertebrate Zoology: A Functional Evolutionary Approach (seventh edition). Thomson Books/Cole, Belmont, California. 
Sadler, C.J. 1993. Arthropod trace fossils from the Permian De Chelly Sandstone, Northeastern Arizona. Journal of Paleontology, 67(2):240-249.

Savrda, C.E. 2007. Taphonomy of trace fossils, p. 92109. In Miller, W. (ed.), Trace Fossils: Concepts, Problems, Prospects. Elsevier, Amsterdam.

Schmerge, J.D., Riese, D.J., and Hasiotis, S.T. 2013. Vinegaroon (Arachnida: Thelyphonida: Thelyphonidae) trackway production and morphology: implications for media and moisture control on trackway morphology and a proposal for a novel system of interpreting arthropod trace fossils. PALAIOS, 28:116-128.

Seilacher, A. 2007. Trace Fossil Analysis. Springer-Verlag, Berlin.

Selden, P.A. 1996. First fossil mesothele spider, from the Carboniferous of France. Revue Suisse de Zoologie, 2:585-596.

Selden, P.A. 2000. Paleothele, replacement name for the fossil mesothele spider Eothele Selden non Rowell. Bulletin-British Arachnological Society, 11(7):292.
Selden, P.A., Anderson, J.M., Anderson, H.M., and Fraser, N.C. 1999. Fossil araneomorph spiders from the Triassic of South Africa and Virginia. Journal of Arachnology, 27:401-414.

Selden, P.A. and Gall, J.C. 1992. A Triassic mygalomorph spider from the northern Vosges, France. Palaeontology, 35:211-235.

Shäfer, W. and Craig, G.Y. 1972. Ecology and Palaeoecology of Marine Environments. Oliver and Boyd, Edinburgh.

Shear, W.A. 1994. Untangling the evolution of the web. American Scientist, 82:256-266.

Smith, A.M. 1990. Baboon Spiders: Tarantulas of Africa and the Middle East. Fitzgerald Publishing, London.

World Spider Catalog. 2017. World Spider Catalog version 18.5, accessed on 7/18/2017. Natural History Museum Bern. http://wsc.nmbe.ch.

Wunderlich, J. 1988. Die fossilen Spinnen im Dominikanischen Bernstein. Beiträge zur Araneologie, 2:1-378. 


\section{APPENDIX 1.}

Video (see online palaeo-electronica.org/content/2017/2003-neoichnology-of-tarantulas) of Aphonopelma chalcodes burrowing through excavation using its pedipalps.

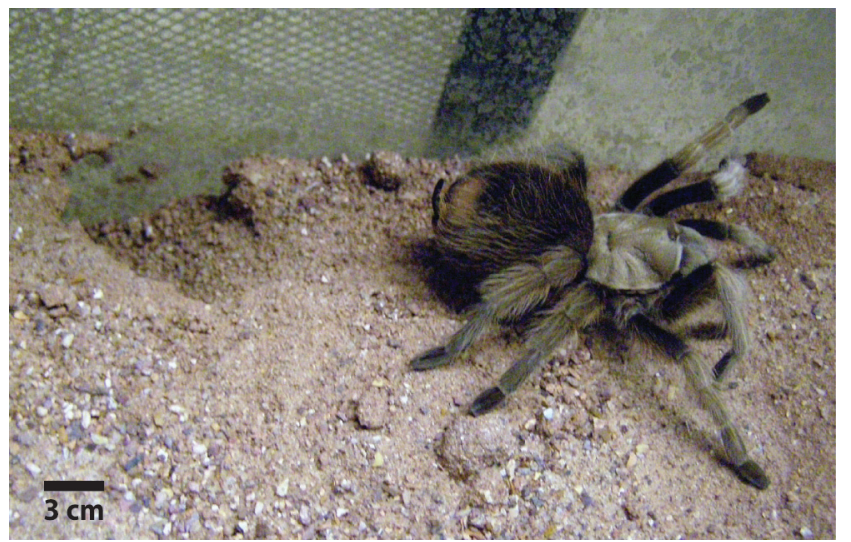




\section{APPENDIX 2.}

Video (see online palaeo-electronica.org/content/2017/2003-neoichnology-of-tarantulas) of burrowing through intrusion.

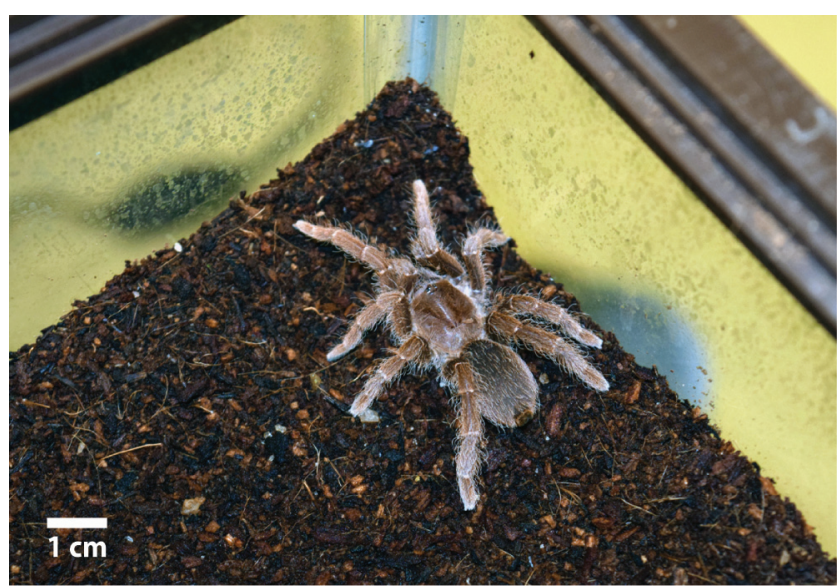




\section{APPENDIX 3.}

Mann-Whitney (MS) and Kolmogorov-Smirnov (KS) test results ( $p$ values) from the comparison of the properties of all burrows produced by Hysterocrates gigas, Pelinobius muticus, and Aphonopelma chalcodes. Yellow highlighted $p$ values are considered significant $(p<0.05)$. The mean, median, standard deviation, and range of each significantly different property is provided for each species. Highlighted values (blue and green) indicate the greater of the two.

\begin{tabular}{|c|c|c|c|c|c|c|c|c|c|c|}
\hline & \multirow[t]{2}{*}{ MW } & \multirow[t]{2}{*}{ KS } & \multicolumn{4}{|c|}{ Hysterocrates gigas } & \multicolumn{4}{|c|}{ Aphonopelma chalcodes } \\
\hline & & & Mean & Median & Std Dev & Range & Mean & Median & Std Dev & Range \\
\hline Surface openings & 1.000 & 1.000 & 1.0 & 1.0 & 0.0 & 1 & 1.0 & 1.0 & 0.0 & 1 \\
\hline Maximum depth & 0.045 & 0.162 & 25.1 & 19.8 & 15.1 & $5.9-53.0$ & 12.0 & 9.8 & 6.0 & $3.1-21.2$ \\
\hline Total length & 0.178 & 0.445 & 36.5 & 25.5 & 25.6 & $6.3-84.0$ & 24.3 & 17.9 & 16.6 & $6.1-58.8$ \\
\hline Maximum width & 0.236 & 0.489 & 8.6 & 8.6 & 2.1 & $3.8-11.6$ & 7.8 & 7.9 & 2.2 & $3.7-11.6$ \\
\hline Minimum width & 0.072 & 0.144 & 3.7 & 3.3 & 1.7 & $1.2-6.8$ & 5.2 & 5.0 & 1.8 & $2.9-8.3$ \\
\hline Mean width & 0.191 & 0.162 & 5.9 & 5.9 & 1.3 & $3.5-8.4$ & 6.6 & 6.6 & 1.4 & $3.4-7.9$ \\
\hline Maximum height & 0.347 & 0.375 & 7.1 & 7.4 & 1.4 & $4.2-8,7$ & 6.3 & 6.7 & 1.6 & $2.4-8.2$ \\
\hline Minimum height & 0.540 & 0.489 & 3.2 & 3.1 & 1.1 & $1.4-5.3$ & 3.2 & 2.5 & 2.1 & $1.2-8.2$ \\
\hline Mean height & 0.902 & 0.995 & 5.1 & 4.9 & 1.0 & $3.3-6.6$ & 4.9 & 5.1 & 1.5 & $1.9-7.0$ \\
\hline Average $\mathrm{W} / \mathrm{H}$ ratio & 0.835 & 0.489 & 1.2 & 1.1 & 0.2 & $1.0-1.7$ & 1.2 & 1.2 & 0.4 & $0.5-1.8$ \\
\hline $\begin{array}{l}\text { Maximum } \\
\text { circumference }\end{array}$ & 0.022 & 0.012 & 25.0 & 24.8 & 4.7 & $13.0-31.0$ & 19.3 & 22.3 & 7.6 & $2.7-25.4$ \\
\hline $\begin{array}{l}\text { Minimum } \\
\text { circumference }\end{array}$ & 0.307 & 0.759 & 12.7 & 11.8 & 5.2 & $4.0-21.0$ & 10.2 & 9.9 & 4.6 & $1.8-17.6$ \\
\hline Mean circumference & 0.487 & 0.375 & 18.5 & 18.6 & 3.3 & $12.2-23.2$ & 16.0 & 18.7 & 6.2 & $2.2-21.7$ \\
\hline Maximum slope & 0.002 & 0.003 & 89.0 & 90.0 & 3.2 & $80-90$ & 57.2 & 55.0 & 24.7 & $25-90$ \\
\hline Minimum slope & 0.215 & 0.341 & 42.5 & 40.0 & 36.2 & $0-90$ & 22.6 & 21.0 & 18.6 & $0-60$ \\
\hline Mean slope & 0.002 & 0.003 & 72.3 & 80.0 & 16.9 & $46-90$ & 37.3 & 28.0 & 17.1 & $25-77$ \\
\hline Complexity & 0.006 & 0.038 & 3.8 & 4.0 & 1.1 & $2-4$ & 2.4 & 2.0 & 0.5 & $2-3$ \\
\hline \multirow[t]{3}{*}{ Tortuosity } & 0.120 & 0.051 & 1.24 & 1.21 & 0.19 & $1.00-1.56$ & 1.28 & 1.04 & 0.53 & $0.98-2.50$ \\
\hline & MW & KS & \multicolumn{4}{|c|}{ Hysterocrates gigas } & \multicolumn{4}{|c|}{ Pelinobius muticus } \\
\hline & & & Mean & Median & Std Dev & Range & Mean & Median & Std Dev & Range \\
\hline Surface openings & 1.000 & 1.000 & 1.0 & 1.0 & 0.0 & 1 & 1.0 & 1.0 & 0.0 & 1 \\
\hline Maximum depth & 0.068 & 0.047 & 25.1 & 19.8 & 15.1 & $5.9-53.0$ & 36.7 & 36.0 & 6.9 & $27.0-48.5$ \\
\hline Total length & 0.056 & 0.012 & 36.5 & 25.5 & 25.6 & $6.3-84.0$ & 56.9 & 56.5 & 12.2 & $42.0-73.0$ \\
\hline Maximum width & 0.005 & 0.001 & 8.6 & 8.6 & 2.1 & $3.8-11.6$ & 4.8 & 4.7 & 0.8 & $4.1-6.5$ \\
\hline Minimum width & 0.050 & 0.149 & 3.7 & 3.3 & 1.7 & $1.2-6.8$ & 2.4 & 2.4 & 0.4 & $1.8-3.2$ \\
\hline Mean width & 0.002 & 0.004 & 5.9 & 5.9 & 1.3 & $3.5-8.4$ & 3.4 & 3.2 & 0.9 & $2.6-5.6$ \\
\hline Maximum height & 0.033 & 0.025 & 7.1 & 7.4 & 1.4 & $4.2-8,7$ & 4.9 & 4.5 & 1.8 & $2.7-8.8$ \\
\hline Minimum height & 0.036 & 0.064 & 3.2 & 3.1 & 1.1 & $1.4-5.3$ & 2.2 & 2.2 & 0.5 & $1.6-2.9$ \\
\hline Mean height & 0.005 & 0.004 & 5.1 & 4.9 & 1.0 & $3.3-6.6$ & 3.4 & 2.9 & 1.0 & $2.2-5.4$ \\
\hline Average $\mathrm{W} / \mathrm{H}$ ratio & 0.259 & 0.738 & 1.2 & 1.1 & 0.2 & $1.0-1.7$ & 1.0 & 1.1 & 0.2 & $0.7-1.2$ \\
\hline $\begin{array}{l}\text { Maximum } \\
\text { circumference }\end{array}$ & 0.003 & 0.001 & 25.0 & 24.8 & 4.7 & $13.0-31.0$ & 15.2 & 14.1 & 2.7 & $12.5-20.5$ \\
\hline $\begin{array}{l}\text { Minimum } \\
\text { circumference }\end{array}$ & 0.021 & 0.047 & 12.7 & 11.8 & 5.2 & $4.0-21.0$ & 8.0 & 7.3 & 1.6 & $6.5-10.5$ \\
\hline Mean circumference & 0.001 & 0.001 & 18.5 & 18.6 & 3.3 & $12.2-23.2$ & 11.0 & 10.5 & 2.4 & $8.3-16.5$ \\
\hline
\end{tabular}


HEMBREE: NeOICHNOLOGY OF tARANTULAS

\begin{tabular}{|c|c|c|c|c|c|c|c|c|c|c|}
\hline Maximum slope & 0.935 & 0.985 & 89.0 & 90.0 & 3.2 & $80-90$ & 88.8 & 90.0 & 3.5 & $80-90$ \\
\hline Minimum slope & 0.032 & 0.012 & 42.5 & 40.0 & 36.2 & $0-90$ & 5.0 & 0.0 & 7.6 & $0-20$ \\
\hline Mean slope & 0.117 & 0.149 & 72.3 & 80.0 & 16.9 & $46-90$ & 59.2 & 57.5 & 10.3 & $48-80$ \\
\hline Complexity & 0.487 & 0.827 & 3.8 & 4.0 & 1.1 & $2-4$ & 4.4 & 4.0 & 1.4 & $3-6$ \\
\hline \multirow[t]{3}{*}{ Tortuosity } & 0.168 & 0.305 & 1.24 & 1.21 & 0.19 & $1.00-1.56$ & 1.44 & 1.46 & 0.33 & $1.07-2.06$ \\
\hline & MW & KS & \multicolumn{4}{|c|}{ Aphonopelma chalcodes } & \multicolumn{4}{|c|}{ Pelinobius muticus } \\
\hline & & & Mean & Median & Std Dev & Range & Mean & Median & Std Dev & Range \\
\hline Surface openings & 1.000 & 1.000 & 1.0 & 1.0 & 0.0 & 1 & 1.0 & 1.0 & 0.0 & 1 \\
\hline Maximum depth & 0.001 & 0.001 & 12.0 & 9.8 & 6.0 & $3.1-21.2$ & 36.7 & 36.0 & 6.9 & $27.0-48.5$ \\
\hline Total length & 0.002 & 0.001 & 24.3 & 17.9 & 16.6 & $6.1-58.8$ & 56.9 & 56.5 & 12.2 & $42.0-73.0$ \\
\hline Maximum width & 0.011 & 0.005 & 7.8 & 7.9 & 2.2 & $3.7-11.6$ & 4.8 & 4.7 & 0.8 & $4.1-6.5$ \\
\hline Minimum width & 0.001 & 0.001 & 5.2 & 5.0 & 1.8 & $2.9-8.3$ & 2.4 & 2.4 & 0.4 & $1.8-3.2$ \\
\hline Mean width & 0.001 & 0.001 & 6.6 & 6.6 & 1.4 & $3.4-7.9$ & 3.4 & 3.2 & 0.9 & $2.6-5.6$ \\
\hline Maximum height & 0.083 & 0.034 & 6.3 & 6.7 & 1.6 & $2.4-8.2$ & 4.9 & 4.5 & 1.8 & $2.7-8.8$ \\
\hline Minimum height & 0.335 & 0.638 & 3.2 & 2.5 & 2.1 & $1.2-8.2$ & 2.2 & 2.2 & 0.5 & $1.6-2.9$ \\
\hline Mean height & 0.048 & 0.029 & 4.9 & 5.1 & 1.5 & $1.9-7.0$ & 3.4 & 2.9 & 1.0 & $2.2-5.4$ \\
\hline Average $\mathrm{W} / \mathrm{H}$ ratio & 0.331 & 0.279 & 1.2 & 1.2 & 0.4 & $0.5-1.8$ & 1.0 & 1.1 & 0.2 & $0.7-1.2$ \\
\hline $\begin{array}{l}\text { Maximum } \\
\text { circumference }\end{array}$ & 0.075 & 0.024 & 19.3 & 22.3 & 7.6 & $2.7-25.4$ & 15.2 & 14.1 & 2.7 & $12.5-20.5$ \\
\hline $\begin{array}{l}\text { Minimum } \\
\text { circumference }\end{array}$ & 0.135 & 0.279 & 10.2 & 9.9 & 4.6 & $1.8-17.6$ & 8.0 & 7.3 & 1.6 & $6.5-10.5$ \\
\hline Mean circumference & 0.043 & 0.005 & 16.0 & 18.7 & 6.2 & $2.2-21.7$ & 11.0 & 10.5 & 2.4 & $8.3-16.5$ \\
\hline Maximum slope & 0.006 & 0.005 & 57.2 & 55.0 & 24.7 & $25-90$ & 88.8 & 90.0 & 3.5 & $80-90$ \\
\hline Minimum slope & 0.025 & 0.029 & 22.6 & 21.0 & 18.6 & $0-60$ & 5.0 & 0.0 & 7.6 & $0-20$ \\
\hline Mean slope & 0.009 & 0.005 & 37.3 & 28.0 & 17.1 & $25-77$ & 59.2 & 57.5 & 10.3 & $48-80$ \\
\hline Complexity & 0.003 & 0.041 & 2.4 & 2.0 & 0.5 & $2-3$ & 4.4 & 4.0 & 1.4 & $3-6$ \\
\hline Tortuosity & 0.048 & 0.005 & 1.28 & 1.04 & 0.53 & $0.98-2.50$ & 1.44 & 1.46 & 0.33 & $1.07-2.06$ \\
\hline
\end{tabular}




\section{APPENDIX 4.}

Quantitative measurements of the burrows of comparative animals. All measurements in $\mathrm{cm}$ or degrees (slope only); W/H ratio, complexity, and tortuosity are unitless. Gl\# = Gorgyrella inermis burrow cast identification number; $\mathrm{Pl}$ = Pandinus imperator burrow cast identification number; $\mathrm{MM \#}=$ Mabuya multifasciata burrow cast identification number; $\mathrm{AT \#}=$ Ambystoma tigrinum burrow cast identification number.

\section{Gorgyrella inermis}

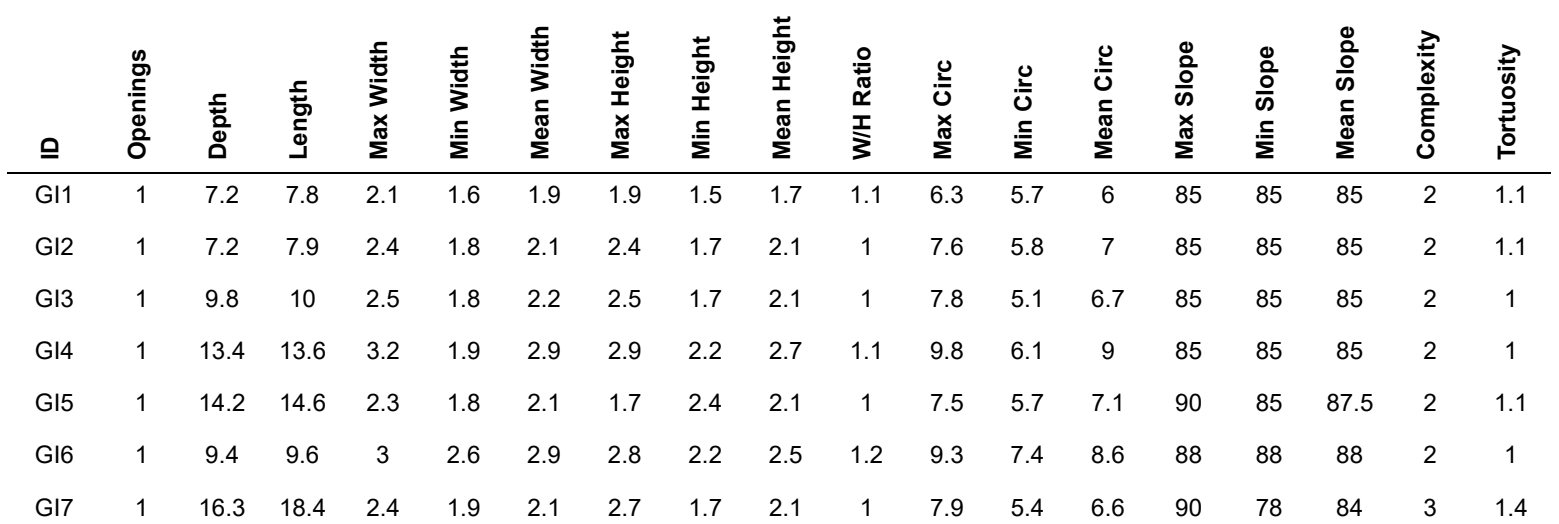

\section{Pandinus imperator}

\begin{tabular}{|c|c|c|c|c|c|c|c|c|c|c|c|c|c|c|c|c|c|c|}
\hline 으 & 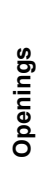 & $\begin{array}{l}\text { 营 } \\
\text { هิ }\end{array}$ & 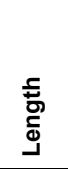 & $\begin{array}{l}\text { F } \\
\stackrel{5}{0} \\
3 \\
x \\
\Sigma \\
\Sigma\end{array}$ & $\begin{array}{l}\frac{5}{5} \\
\frac{5}{3} \\
\frac{c}{\Sigma} \\
\Sigma\end{array}$ & 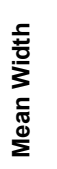 & $\begin{array}{l}\frac{ \pm}{5} \\
\frac{0}{0} \\
\frac{0}{T} \\
x \\
\frac{x}{2}\end{array}$ & 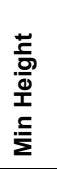 & 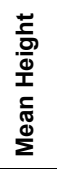 & 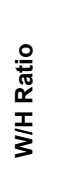 & $\begin{array}{l}\stackrel{0}{\Xi} \\
\dot{U} \\
\stackrel{x}{\Sigma}\end{array}$ & $\begin{array}{l}0 \\
\dot{U} \\
\frac{\Xi}{\Sigma}\end{array}$ & 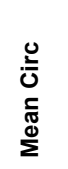 & $\begin{array}{l}\searrow \\
\frac{0}{0} \\
\infty \\
\frac{x}{\pi} \\
\Sigma\end{array}$ & 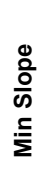 & 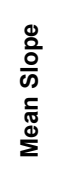 & $\begin{array}{l}\frac{7}{x} \\
\frac{d}{0} \\
\frac{0}{\partial} \\
0\end{array}$ & 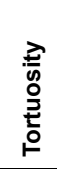 \\
\hline $\mathrm{PI} 1$ & 1 & 6.5 & 28 & 7.6 & 6 & 6.7 & 4.4 & 2.9 & 3.7 & 1.8 & 23.5 & 17.5 & 19.3 & 20 & 15 & 17 & 3 & 1 \\
\hline $\mathrm{PI} 2$ & 1 & 5 & 18 & 6.3 & 3.6 & 5.6 & 3.6 & 2.2 & 2.8 & 2 & 18 & 12 & 15.1 & 20 & 0 & 13 & 3 & 1.1 \\
\hline PI3 & 1 & 13 & 34 & 11.6 & 3.9 & 8.2 & 4.2 & 1.9 & 2.9 & 2.8 & 28 & 10 & 19.7 & 50 & 0 & 19.3 & 3 & 1.1 \\
\hline PI4 & 1 & 6 & 29 & 7.1 & 3.8 & 6.3 & 3.8 & 1.7 & 2.9 & 2.2 & 19.5 & 12 & 17 & 20 & 0 & 6.7 & 3 & 1 \\
\hline PI5 & 1 & 7 & 19.5 & 6.3 & 4.8 & 5.8 & 2.7 & 1.8 & 2.5 & 2.3 & 16 & 13 & 15.2 & 20 & 0 & 13 & 2 & 1 \\
\hline PI6 & 1 & 12.5 & 34 & 12 & 7.4 & 9.6 & 7.1 & 3 & 3.9 & 2.5 & 28.5 & 20.5 & 24.8 & 30 & 0 & 14 & 3 & 1.7 \\
\hline PI7 & 1 & 16 & 34 & 11.3 & 5.5 & 8.7 & 5.4 & 3.9 & 4.5 & 1.9 & 27.1 & 12.2 & 21.5 & 30 & 0 & 24 & 3 & 1.1 \\
\hline PI8 & 1 & 14 & 29 & 6.4 & 4.3 & 5.5 & 3.4 & 2.1 & 2.7 & 2 & 16 & 11 & 14.1 & 50 & 0 & 21 & 3 & 1.1 \\
\hline PI9 & 1 & 15 & 32 & 8.3 & 4.2 & 6.5 & 5.9 & 2 & 4.5 & 1.4 & 22.5 & 12.5 & 19 & 30 & 0 & 18 & 3 & 1.5 \\
\hline
\end{tabular}

Mabuya multifasciata

\begin{tabular}{|c|c|c|c|c|c|c|c|c|c|c|c|c|c|c|c|c|c|c|}
\hline 으 & 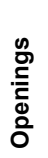 & $\begin{array}{l}\frac{5}{0} \\
\frac{0}{\Delta}\end{array}$ & 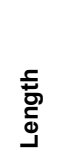 & 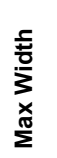 & 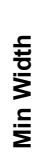 & 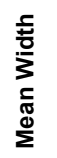 & 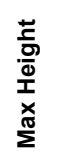 & 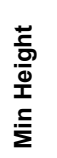 & 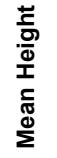 & 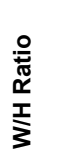 & 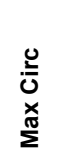 & 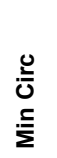 & 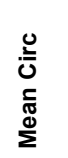 & $\begin{array}{l}\frac{\Xi}{0} \\
\frac{0}{\infty} \\
\stackrel{x}{\Sigma}\end{array}$ & $\begin{array}{l}\nsubseteq \\
\frac{0}{0} \\
\check{\Sigma} \\
\dot{\Sigma}\end{array}$ & $\begin{array}{l}\text { \% } \\
\text { 은 } \\
\text { ॠ } \\
\stackrel{\Xi}{\Sigma}\end{array}$ & 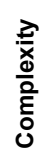 & $\begin{array}{l}\vec{Z} \\
\frac{1}{0} \\
\circ \\
\stackrel{0}{ \pm} \\
\stackrel{0}{0}\end{array}$ \\
\hline MM1 & 1 & 2.3 & 6.5 & 2.2 & 1.9 & 2 & 2 & 1.3 & 1.6 & 1.3 & 7.4 & 6.8 & 7.2 & 51 & 4 & 28 & 2 & 1.0 \\
\hline MM2 & 1 & 5.4 & 28.7 & 5.3 & 2.2 & 4 & 3 & 1.9 & 2.5 & 1.6 & 13.9 & 7 & 11.9 & 32 & 6 & 19 & 2 & 1.2 \\
\hline MM3 & 1 & 5.3 & 19.6 & 5.1 & 1.9 & 3.3 & 2.6 & 1.5 & 2.1 & 1.6 & 12.5 & 6.5 & 9.3 & 42 & 5 & 24 & 3 & 1.1 \\
\hline MM4 & 1 & 2.8 & 11 & 3.5 & 2.4 & 2.8 & 2.7 & 1.6 & 2 & 1.4 & 9.7 & 7.2 & 8.4 & 55 & 28 & 42 & 2 & 1.2 \\
\hline MM5 & 1 & 4.8 & 11 & 2.5 & 2.1 & 2.3 & 5.6 & 2.4 & 3.6 & 0.7 & 14.2 & 8.1 & 10.8 & 30 & 7 & 19 & 2 & 1.2 \\
\hline MM6 & 1 & 5 & 14.5 & 2.6 & 1.9 & 2.3 & 2.4 & 1.4 & 1.8 & 1.3 & 8.2 & 6.1 & 6.9 & 45 & 10 & 28 & 2 & 1.2 \\
\hline MM7 & 1 & 3.8 & 10.8 & 4.5 & 2.2 & 3.1 & 2.9 & 1.4 & 2.4 & 1.3 & 11.8 & 5.5 & 8.5 & 48 & 3 & 26 & 2 & 1.0 \\
\hline
\end{tabular}


HEMBREE: NEOICHNOLOGY OF TARANTULAS

$\begin{array}{lllllllllllllllllll}\text { MM8 } & 1 & 9.4 & 11.6 & 4.3 & 2 & 2.8 & 3.4 & 1.5 & 2.2 & 1.2 & 14.2 & 6.4 & 9.6 & 62 & 35 & 49 & 2 & 1.2\end{array}$

Ambystoma tigrinum

\begin{tabular}{|c|c|c|c|c|c|c|c|c|c|c|c|c|c|c|c|c|c|c|}
\hline 으 & 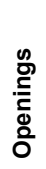 & 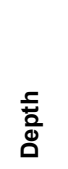 & 䓌 & 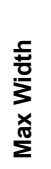 & 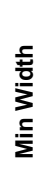 & 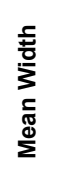 & 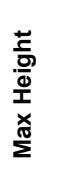 & 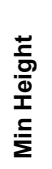 & 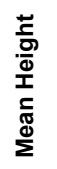 & 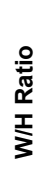 & 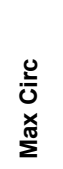 & $\begin{array}{l}0 \\
\frac{0}{U} \\
\frac{5}{\Sigma}\end{array}$ & $\begin{array}{l}\text { U. } \\
\frac{0}{0} \\
\frac{0}{\mathbb{J}} \\
\Sigma\end{array}$ & $\begin{array}{l}\searrow \\
\text { 을 } \\
\text { क } \\
\times \\
\stackrel{\pi}{\Sigma}\end{array}$ & $\begin{array}{l}\frac{\Xi}{0} \\
\frac{0}{\infty} \\
\Sigma \\
\Sigma\end{array}$ & 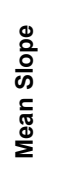 & $\begin{array}{l}\frac{\mathbb{x}}{x} \\
\frac{0}{0} \\
\frac{0}{\partial} \\
0\end{array}$ & 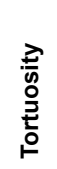 \\
\hline AT1 & 1 & 5.8 & 9.8 & 3.3 & 1.2 & 2.1 & 2.2 & 1.1 & 1.5 & 1.4 & 13 & 4.5 & 9.8 & 35 & 35 & 35 & 2 & 1.5 \\
\hline AT2 & 1 & 9.3 & 19.5 & 5 & 1.6 & 3.5 & 3.1 & 1.6 & 2.4 & 1.5 & 11.3 & 6.1 & 9.3 & 67 & 67 & 67 & 2 & 1.3 \\
\hline AT3 & 1 & 4 & 11.3 & 4.1 & 1.9 & 3.2 & 2.8 & 1.6 & 2.1 & 1.5 & 11.1 & 6.1 & 8.3 & 31 & 31 & 31 & 2 & 1.3 \\
\hline AT4 & 1 & 7.5 & 9 & 2.1 & 0.9 & 1.7 & 1.7 & 1.1 & 1.5 & 1.1 & 7.2 & 4.3 & 6 & 64 & 64 & 64 & 2 & 1.2 \\
\hline AT5 & 1 & 9.8 & 13 & 4.5 & 2.9 & 3.8 & 3.4 & 2.6 & 2.8 & 1.4 & 11.6 & 9.3 & 10.5 & 53 & 53 & 53 & 2 & 1.1 \\
\hline AT6 & 1 & 12.4 & 15.5 & 3.5 & 2.4 & 2.9 & 2.5 & 1.3 & 1.9 & 1.5 & 9 & 6.4 & 7.6 & 65 & 65 & 65 & 2 & 1 \\
\hline AT7 & 1 & 8.7 & 12.5 & 3.6 & 2.3 & 3 & 3.2 & 1.5 & 2.2 & 1.4 & 10.6 & 6.9 & 8.2 & 62 & 62 & 62 & 2 & 1.3 \\
\hline AT8 & 1 & 5.2 & 10 & 3 & 2.1 & 2.7 & 2 & 1.5 & 1.8 & 1.5 & 8.4 & 6.2 & 7.3 & 40 & 40 & 40 & 2 & 1.6 \\
\hline AT9 & 1 & 4.2 & 11.3 & 2.5 & 2 & 2.2 & 2.6 & 1.6 & 2 & 1.1 & 8.6 & 5.8 & 7.5 & 40 & 40 & 40 & 2 & 1.3 \\
\hline
\end{tabular}

